\title{
THE ENVIRONMENTAL INDUCTION OF HERITABLE CHANGE IN LINUM
}

\author{
ALAN DURRANT \\ Department of Agricultural Botany, University College of Wales, \\ Aberystwyth
}

\section{INTRODUCTION}

Received ro.vii.6

IT is a matter of common observation that responses to nutritional and climatic differences are not as a general rule transmitted from one generation to the next. The most that can be said is that, first, possibly some unique situation might arise involving a particular genotype and a particular environment where such a heritable change does occur, but of itself having no general application. Second, all observations may have been made on material suitable for the investigators, but not for demonstrating the heritable changes. The most convenient materials are inbred, homozygous strains, which are likely to be varieties of crop plants bred for high yield in good cultural conditions and fertile soils. These have been selected for genetic responses to good environmental conditions to give a phenotype which is economically useful, and are not representative of naturally occurring organisms. Third, it has received insufficient attention in biological investigations.

There is ample evidence, apart from mutation, of the effectiveness of the environment at all levels in inducing specific types of heritable change. These may be enumerated as follows: (i) Induced quantitative changes in cytoplasmic particles (e.g. Sonneborn, 1950). (ii) Enzyme induction in micro-organisms (e.g. Spiegelman and Campbell, 1956). (iii) Cytoplasmic incorporation of proviruses (e.g. Malogolowkin, Poulson and Wright, 1959). (iv) Phage transduction (e.g. Hartman, 1957). (v) Bacterial transformation (e.g. Avery, MacLeod and McCarty, 1944). (vi) Differentiation of multicellular organisms (e.g. Waddington, i956). (vii) Paramutation (e.g. Brink, 1956; Brink, Blackwood and Notani, 196o; Schaik and Brink, 1959). On these grounds there is no reason to believe that environmentally induced heritable changes of the more general type cannot occur, but if organisms can be effectively changed in one generation by prevailing nutritional and climatic factors, so they should also in the next, and no heritable change would be observed. On the other hand, should there be genetic variability among organisms in their ability to maintain, or return to, a metabolic state that allows response to environmental conditions in successive generations, then heritable changes will be seen to occur in some organisms in some environments.

Extensive experiments have been carried out during the past seven years, mainly with a single variety of flax (Linum usitatissimum), on the transmission of responses to fertiliser treatments applied in one 
generation, to subsequent generations. Large heritable changes have been found to occur. The experiments began in 1953 with studies on the response of several varieties of flax and linseed, and their $F_{1} s$ and $\mathrm{F}_{2} \mathrm{~s}$, to the application of all combinations of nitrogen, potassium, phosphorus and calcium, the object being to obtain information on their homeostatic properties, gene/environment interaction, gene interaction and dominance, etc., for a number of characters in the different environments. Flax and linseed were used because of the interesting comparisons likely to be given by two distinct types of the. one species, Linum usitatissimum, bred for different characteristics. For several reasons, some experiments were also carried out to determine whether any variability was transmitted from the parents.

First, it was necessary that this should be checked in view of the type of experiment envisaged. Second, in other work in the department on inbred lines of Drosophila melanogaster, where the flies had been sib-mated for many hundreds of generations, a large part of the variability in sternopleural chaeta number was due to the age of the female parent (Durrant, I955a), and the chaeta number of the offspring could also be altered by varying the amount of food and rate of egg laying of the female parent-changes which are probably either cytoplasmic or maternal (Durrant, 1955b). Third, flax, unlike linseed and other crop plants, has not been bred for seed yield, plant weight or plant size but for a relatively long, unbranched stem with few seeds, and normally grown with as much as one plant to the square inch in a well established crop. Flax plants might therefore be expected to be less stable than other crop plants. Fourth, special references have been made in the literature to flax seed. Percival (1935) states, for example,

"The best yield of flax, so far as fibre is concerned, is said by some to be obtained from seed which has been carefully dried and kept in tightly closed barrels which exclude moisture for two or threc years, experiments having shown that seed stored in this way gives longer stems and finer bast than fresh seed; others consider that the highest yield of fibre is secured from the fully ripened seed, harvested from a crop raised from 'barrel 'flax."

Greater importance is attached to the weight of flax seed than with most other crops, seed weighing less than 4 grams per 1000 being considered to give a poor flax crop.

In a preliminary study, seed was collected from branches which had been pruned to leave only two capsules per branch to develop, and also from unpruned branches, of 10 flax varieties, and sown the following year. At maturity the plants from seed from the pruned branches showed an increase in height of 10 per cent. over plants from seed from the unpruned branches. Two linseed varieties which were similarly treated gave no significant response. Another experiment was therefore begun, and run concurrently with the main experiment, where seed of one of the flax varieties was collected from 
plants growing in all combinations of nitrogen, phosphorus and potassium fertiliser treatments, and sown the following year. The progeny showed large differences in weight, a result which initiated the further studies which are to be described.

\section{SYMBOLS}

Upper-case letters are used in making general reference to the fertilisers applied in these experiments, and also to their main effects and interactions, namely $\mathrm{N}$ (sulphate of ammonia), $\mathrm{P}$ (granular triple superphosphate), $\mathrm{K}$ (potassium chloride) and $\mathrm{G}$ (calcium hydrate, here referred to as a fertiliser). Lower-case letters, for example, $\mathrm{npkg}$, $\mathrm{nkg}, \mathrm{n}, \mathrm{pk}$, denote the combinations of fertilisers applied, and (I) denotes no application.

TABLE I

Example of designations

\begin{tabular}{|c|c|c|c|}
\hline Treatment & $\begin{array}{l}\text { Year in which } \\
\text { treatment } \\
\text { applied }\end{array}$ & Designation & $\begin{array}{c}\text { Abbreviation } \\
\text { (environmental } \\
\text { history) }\end{array}$ \\
\hline $\begin{array}{l}\text { np } \\
\text { nk } \\
\text { (1) } \\
\text { npk }\end{array}$ & $\begin{array}{l}1954 \\
1955 \\
1956 \\
1957\end{array}$ & 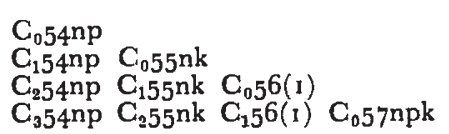 & $\begin{array}{l}\text { Stock } \\
\text { np } \\
\text { np, nk } \\
\text { np, nk, (1) }\end{array}$ \\
\hline
\end{tabular}

Plants receiving the fertilisers are the parental generation, denoted $\mathrm{C}_{0}$, and the Ist, $2 \mathrm{nd}, 3 \mathrm{rd}$, etc. generations from them are denoted $\mathrm{C}_{1}, \mathrm{C}_{2}, \mathrm{C}_{3}$, etc. Plants are further designated by the treatments applied to them or their ancestors and, where necessary, by the year in which they were applied (not the year in which the particular generation was grown as used previously, Durrant, I958). For example plants receiving both $N$ and $P$ in 1954 are denoted $C_{0} 54 \mathrm{np}$, the first generation grown the following year, $\mathrm{C}_{154 \mathrm{np}}$, and the second generation, $\mathrm{C}_{2} 54 \mathrm{np}$.

Fertilisers applied to the descendants of the parental generation are parental treatments for further descendants and in this way successive generations accumulate several designations, as illustrated in table I. It is more convenient to classify plants according to their environmental history, and in abbreviating these designations the $\mathrm{C}_{0}$ designation is omitted, as shown in the last column of table I. The environment in which the plants are growing in any generation under consideration is then stated separately, or, if added to the environmental history, prefixed by $\mathrm{C}_{0}$, as for example, for the year 1957 in table I, np, nk, (I), $\mathrm{C}_{0} 57 \mathrm{npk}$.

\section{THE ENVIRONMENT}

The seed was sown in boxes in a warm greenhouse where they received solutions of commercial fertilisers and the young plants were 
transplanted into field plots which had received the same commercial fertilisers as the plants had received in the boxes. Each individual was traced from the seed to the mature plant so that selection could not occur unnoticed and seed contamination was prevented.

The field belonged to the college farm up to and including 1953. It was grazing land in 1949, I950 and 1951, cropped with a feeding mixture in $195^{2}$ and with oats undersown with a grass/clover mixture in 1953. In 1952 and 1953 it received a total of $4 \mathrm{cwt}$. of compound fertiliser, $5 \mathrm{cwt}$. of basic slag and $30 \mathrm{cwt}$. of ground limestone, per acre. The soil is a light to medium loam and, characteristic of the soils in the area, has a low available phosphate content.

The fertilisers were sulphate of ammonia $(\mathrm{N})$, muriate of potash $(\mathrm{K})$, granular triple superphosphate $(\mathrm{P})$ and lime, applied as calcium hydrate $(G)$. The sixteen combinations of $N, P, K$ and $G$ each at two levels, applied and not applied, were laid out in the field in 1954 and established as permanent plots. In 1954 each fertiliser was applied to the appropriate plots at the rate of $6 \mathrm{cwt}$. per acre, except for lime which was applied at the rate of $15 \mathrm{cwt}$. per acre. The npkg plots therefore had $15 \mathrm{cwt}$. per acre of lime and a total of $18 \mathrm{civt}$. per acre of the remaining fertilisers. In subsequent years the same quantity of fertilisers was applied to the plots each year.

The greenhouse compost was made from 7 parts soil from the field, 3 parts Irish granulated moss peat and 2 parts granite chippings. The solutions were made by dissolving 15 grams each of $\mathrm{N}, \mathrm{P}$ and $\mathrm{K}$ in a litre of water according to the combination required so that npk, for example, was applied as a 4.5 per cent. solution. To obtain the phosphate in solution the granular triple superphosphate was left in water for 24 hours, shaken at intervals and the solution syphoned off. Two hundred and fifty c.c. of the appropriate solution was applied at sowing to each box measuring approximately $9 \times 14 \times 4$ in. deep. The same quantity was applied io days later but using solutions one-sixth the strength. After each application the boxes were lightly rinsed with water. Where lime was required ground limestone was mixed with the compost at the rate of one ounce to the cwt. The plants remained in the warm greenhouse for two to five weeks depending on the season and space available, placed in a cool greenhouse for one to two weeks and left outside until they were transplanted between the ages of four and seven weeks. Just before transplanting, the soil in the boxes was rinsed with a $0 \cdot 1$ per cent. solution of Gammelin C.L., this being an effective control of wireworm which would otherwise have caused large losses in the field. For some of the later experiments it was sufficient to grow all the plants under uniform, reasonably fertile soil conditions and for this purpose a compound fertiliser and lime were applied to part of the field, and John Innes base fertiliser and lime added to the compost used in the greenhouse.

The fertilisers can be applied with a fair degree of accuracy but 
it is of course impossible to ensure the same environmental conditions each year. In the first place, the general fertility of the field, maintained at a reasonable level prior to its use for these experiments, decreased year by year so that fertilisers which had little or no effect in the first year, had a pronounced effect in later years. Seasonal variations produced large environmental differences, drought at transplanting time being a particularly potent factor. Severe drought at transplanting time, lasting perhaps for six weeks, caused considerable losses in some experiments and these had to be written off, and plants in experiments without losses have a vastly different environment from plants transplanted in a wet, early summer. Sowing of seed generally commenced at the end of March but continued for as much as a month afterwards, mainly because of limitations of time and space, and transplanting was also spaced out over a similar period of time. This time-difference again results in year to year environmental differences and is the principal reason why all the plants in some experiments survive during drought, while the loss in others renders those experiments virtually useless. The seasons interact with the fertiliser treatments, the more so because of the large differences in size and vigour of the plants due to the fertilisers applied to the boxes, only some of the plants being ideally suited for transplanting at any one time, the others being too large or too small. The use of pot cultures would have removed some of these difficulties but they would also have limited the experiments because, apart from the more artificial environment they provide, it would have been possible to grow only a small fraction of the number of plants each year that were grown, and the seasonal effects themselves supply additional information -if these can be correctly construed. It will become evident that it is necessary for the progeny of plants treated also to be grown under a range of treatments and if pot cultures were used for the parental treatments and larger numbers of plants of the first generation were planted into the field the following year there would arise the further problem of relating the two sets of treatments. With the results of these preliminary expcriments now to hand pot cultures would undoubtedly be of more use.

The environments applied to the plants are, in effect, as much applications of convenience as they are purposeful. They differ from those normally experienced by growing crops in the large amounts of fertiliscrs applied, the spacing of the plants in the field at 12-inch intervals in rows 24 inches apart, and in the higher temperature, and probably higher humidity, thcy reccive in the greenhouse during the first few weeks of their growth.

\section{THE INDUCTION OF HERITABLE CHANGE}

\section{Experiment 1-(i) Origin of the seed and the parental generation}

Seed of the variety Stormont Cirrus was kindly supplied by the Plant Breeding Station at Stormont in Northern Ireland. In 
I953 it was sown in boxes outside the greenhouse and the plants transplanted (along with other varieties) into small observation plots which had not recently received fertilisers. The boxes contained the same soil, which was not made up into compost, as in the observation plots and no fertiliser was applied to the boxes or to the plots.

TABLE 2

Plant weights (oz.) in the Ist generation of Experiment $I$.

Means of five plants

\begin{tabular}{|c|c|c|c|c|c|c|c|c|c|c|}
\hline & \multicolumn{8}{|c|}{$\mathrm{C}_{154}$} & \multirow{2}{*}{$\begin{array}{l}\text { Total } \\
\text { (A) }\end{array}$} & \multirow{2}{*}{$\begin{array}{l}\text { Total } \\
\text { (B) }\end{array}$} \\
\hline & npk & $\mathrm{np}$ & nk & $\mathrm{n}$ & pk & $\mathrm{p}$ & k & (I) & & \\
\hline $\begin{array}{c}\mathrm{C}_{055} \\
\mathrm{npkg} \\
\mathrm{npk}\end{array}$ & $\begin{array}{l}4 \cdot 0 \\
2 \cdot 8\end{array}$ & $\begin{array}{l}1 \cdot 5 \\
2 \cdot 8\end{array}$ & $\begin{array}{l}1.2 \\
0.5\end{array}$ & $\begin{array}{l}3.5 \\
2 \cdot 3\end{array}$ & $\begin{array}{l}3 \cdot 3 \\
2 \cdot 0\end{array}$ & $\begin{array}{l}3 \cdot 7 \\
2 \cdot 0\end{array}$ & $\begin{array}{l}2 \cdot 4 \\
2 \cdot 1\end{array}$ & $\begin{array}{l}1 \cdot 5 \\
1 \cdot 0\end{array}$ & $\begin{array}{l}21 \cdot 1 \\
15.5\end{array}$ & $3^{6} \cdot 6$ \\
\hline $\begin{array}{l}\text { npg } \\
\text { np }\end{array}$ & $\begin{array}{l}3 \cdot 7 \\
2 \cdot 3\end{array}$ & $\begin{array}{l}3.3 \\
1.9\end{array}$ & $\begin{array}{l}1.2 \\
0.7\end{array}$ & $\begin{array}{l}3 \cdot 6 \\
2 \cdot 3\end{array}$ & $\begin{array}{l}3 \cdot 0 \\
2 \cdot 2\end{array}$ & $\begin{array}{l}4.2 \\
1.6\end{array}$ & $\begin{array}{l}2 \cdot 9 \\
2 \cdot 5\end{array}$ & $\begin{array}{l}1.7 \\
0.9\end{array}$ & $\begin{array}{l}23 \cdot 6 \\
14.4\end{array}$ & $3^{8 \cdot 0}$ \\
\hline $\begin{array}{l}\text { nkg } \\
\text { nk }\end{array}$ & $\begin{array}{l}\mathrm{I} \cdot 8 \\
0.8\end{array}$ & $\begin{array}{l}0.8 \\
0.2\end{array}$ & $\begin{array}{l}0.8 \\
0.4\end{array}$ & $\begin{array}{l}2 \cdot 0 \\
0.5\end{array}$ & $\begin{array}{l}1 \cdot 2 \\
1 \cdot 0\end{array}$ & $\begin{array}{l}0.8 \\
0.4\end{array}$ & $\begin{array}{l}1.7 \\
0.3\end{array}$ & $\begin{array}{l}1 \cdot 3 \\
0.3\end{array}$ & $\begin{array}{r}10.4 \\
3.9\end{array}$ & 14.3 \\
\hline $\begin{array}{l}\mathrm{ng} \\
\mathrm{n}\end{array}$ & $\begin{array}{l}1 \cdot 6 \\
1 \cdot 0\end{array}$ & $\begin{array}{l}1.8 \\
1.0\end{array}$ & $\begin{array}{l}1.0 \\
0.5\end{array}$ & $\begin{array}{l}0.9 \\
1.2\end{array}$ & $\begin{array}{l}1 \cdot 7 \\
2 \cdot 1\end{array}$ & $\begin{array}{l}1.5 \\
0.8\end{array}$ & $\begin{array}{l}1 \cdot 2 \\
1 \cdot 2\end{array}$ & $\begin{array}{l}1.1 \\
0.8\end{array}$ & $\begin{array}{r}10.8 \\
8.6\end{array}$ & 19.4 \\
\hline $\begin{array}{l}\text { pkg } \\
\text { pk }\end{array}$ & $\begin{array}{l}2 \cdot 2 \\
2 \cdot 7\end{array}$ & $\begin{array}{l}2 \cdot 1 \\
2 \cdot 2\end{array}$ & $\begin{array}{l}0.7 \\
0.3\end{array}$ & $\begin{array}{l}3 \cdot 3 \\
2 \cdot 9\end{array}$ & $\begin{array}{l}3 \cdot 0 \\
2 \cdot 8\end{array}$ & $\begin{array}{l}2.4 \\
0.6\end{array}$ & $\begin{array}{l}2 \cdot 5 \\
1 \cdot 1\end{array}$ & $\begin{array}{l}1.4 \\
0.5\end{array}$ & $\begin{array}{r}17.6 \\
13.1\end{array}$ & $30 \cdot 7$ \\
\hline $\begin{array}{l}\mathrm{pg} \\
\mathrm{p}\end{array}$ & $\begin{array}{l}2 \cdot 3 \\
2 \cdot 5\end{array}$ & $\begin{array}{l}1.7 \\
2.9\end{array}$ & $\begin{array}{l}0.7 \\
0.8\end{array}$ & $\begin{array}{l}3 \cdot 1 \\
3 \cdot 8\end{array}$ & $\begin{array}{l}2 \cdot 5 \\
3 \cdot 0\end{array}$ & $\begin{array}{l}2 \cdot 6 \\
1 \cdot 3\end{array}$ & $\begin{array}{l}0.8 \\
1.0\end{array}$ & $\begin{array}{l}1.4 \\
2.8\end{array}$ & $\begin{array}{l}15.1 \\
18.1\end{array}$ & $33 \cdot 2$ \\
\hline $\begin{array}{l}\mathrm{kg} \\
\mathrm{k}\end{array}$ & $\begin{array}{l}2 \cdot 6 \\
1 \cdot 9\end{array}$ & $\begin{array}{l}2 \cdot 2 \\
2 \cdot 3\end{array}$ & $\begin{array}{l}0.7 \\
0.8\end{array}$ & $\begin{array}{l}3 \cdot 0 \\
2 \cdot 3\end{array}$ & $\begin{array}{l}1 \cdot 8 \\
2 \cdot 3\end{array}$ & $\begin{array}{l}1.6 \\
1.0\end{array}$ & $\begin{array}{l}1 \cdot 6 \\
2 \cdot 1\end{array}$ & $\begin{array}{l}1 \cdot 0 \\
1 \cdot 3\end{array}$ & $\begin{array}{l}14.5 \\
14.0\end{array}$ & $28 \cdot 5$ \\
\hline$\underset{(\mathrm{I})}{\mathrm{g}}$ & $\begin{array}{l}1 \cdot 5 \\
2 \cdot 1\end{array}$ & $\begin{array}{l}2 \cdot 0 \\
1.8\end{array}$ & $\begin{array}{l}0.6 \\
0.8\end{array}$ & $\begin{array}{l}2.4 \\
1.6\end{array}$ & $\begin{array}{l}1.6 \\
2 \cdot 7\end{array}$ & $\begin{array}{l}1.0 \\
1.3\end{array}$ & $\begin{array}{l}0.9 \\
0.9\end{array}$ & $\begin{array}{l}1.3 \\
0.9\end{array}$ & $\begin{array}{l}11 \cdot 3 \\
12 \cdot 1\end{array}$ & 23.4 \\
\hline Total & $35 \cdot 8$ & $30 \cdot 5$ & $11 \cdot 7$ & $38 \cdot 7$ & $36 \cdot 2$ & $26 \cdot 8$ & $25 \cdot 2$ & 19.2 & $224 \cdot 1$ & $224 \cdot 1$ \\
\hline
\end{tabular}

Least significant differences for $P=0.05$ :

$$
\begin{aligned}
& \mathrm{C}_{055} \text { totals (A) . . . . } 8 \cdot 3^{8}
\end{aligned}
$$

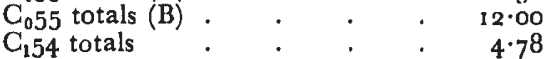

Flower buds were bagged on several plants and seed from eight capsules, four from each of two plants, used for experiments which began in 1954 .

In 1954 five seeds were sown in each of eight boxes to which were added the eight combinations of N, P and $\mathrm{K}$. No lime was added. The plants were transplanted into the eight respective fertiliser treatments in the field and at maturity seed was collected from the five plants in each treatment. The flower buds had previously been bagged and individual plants within each plot contributed approximately equal amounts of seed. Seed from this parental generation, $\mathrm{C}_{054}$, therefore consisted of eight types, $n p k, n p, n k, n, p k, p, k$ and (I). 


\section{(ii) The first generation}

The first generation, $\mathrm{C}_{\mathbf{1}} 54$, was grown the following year in all combinations of $\mathrm{N}, \mathrm{P}, \mathrm{K}$ and $\mathrm{G}$. There were sixteen replications of the eight ist generation types, two boxes per replication and four rows of six seeds per box. The eight seed samples, $\mathrm{C}_{\mathbf{1}} 54$, were assigned at random to the eight rows in each pair of boxes and the sixteen $\mathrm{C}_{055}$ combinations of $\mathrm{N}, \mathrm{P}, \mathrm{K}$ and $\mathrm{G}$ assigned at random to the sixteen replications, giving 128 combinations of $\mathrm{C}_{154}$ and $\mathrm{C}_{055}$ altogether. Out of a total of $768 \mathrm{seed}$, 10 failed to germinate and two

TABLE 3

Analysis of variance of plant weights in the rst generation of experiment I

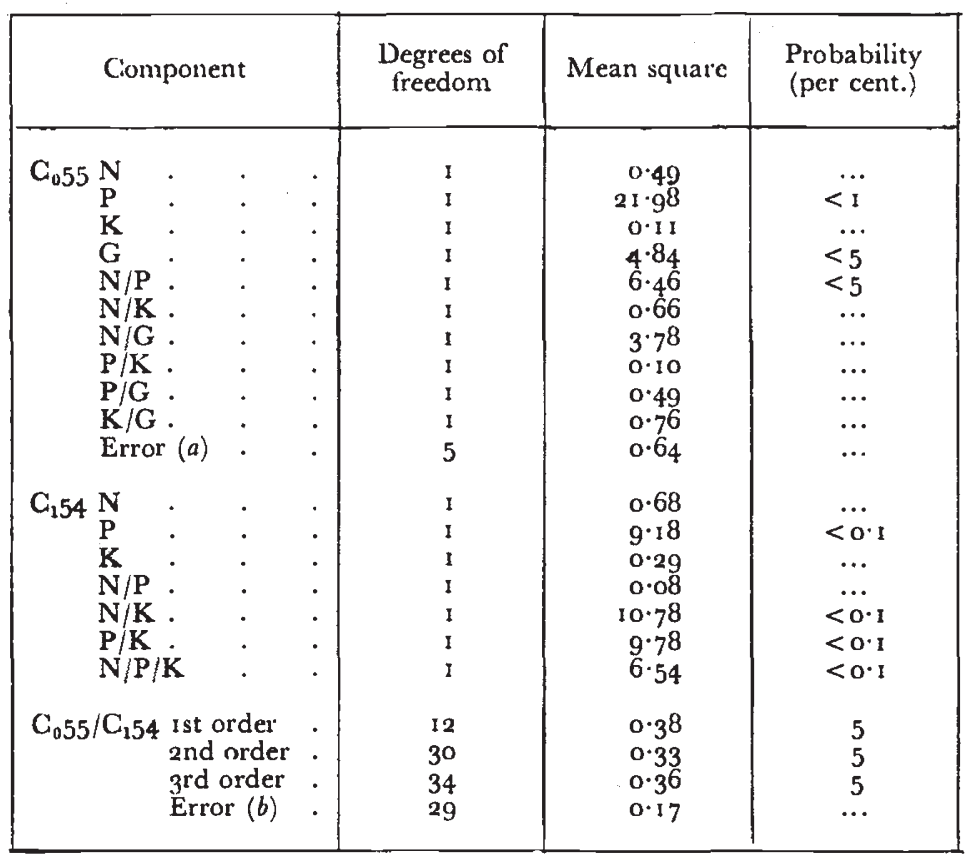

seedlings were either abnormal or damaged. Four of those which failed to germinate were in the $\mathrm{C}_{154 \mathrm{nk}}$ seed sample, the others scattered over the other $\mathrm{C}_{154}$ samples. Five plants from each row were transplanted into the field, the sixth having been sown as insurance against poor germination or damage. In the field the eight $\mathrm{C}_{154}$ types were randomised in each of the sixteen combinations of fertiliser treatments. These sixteen $\mathrm{C}_{055}$ combinations of treatments applied to the $\mathrm{C}_{154}$ plants may be regarded as another set of parental treatments for subsequent generations of plants.

A sample of ripe seed was collected from each of the 128 plots, all five plants in each plot contributing approximately equally to each sample as before, but the flower buds were not bagged. The plants were cut at ground level and weighed and the mean fresh weight of the five plants in each row is given in table 2 where the 
transmitted effects, $\mathrm{C}_{154}$, and the direct effects, $\mathrm{C}_{055}$, of the fertilisers can be compared in the same group of plants. The analysis in table 3 shows that there are highly significant differences in both sets. The $\mathrm{C}_{055}$ treatment totals are less sensitively tested than the $\mathrm{C}_{154}$ totals due to the split-plot design of the experiment, but among the main effects in both cases, phosphorus, $\mathrm{C}_{055} \mathrm{P}$ and $\mathrm{C}_{154} \mathrm{P}$, has the

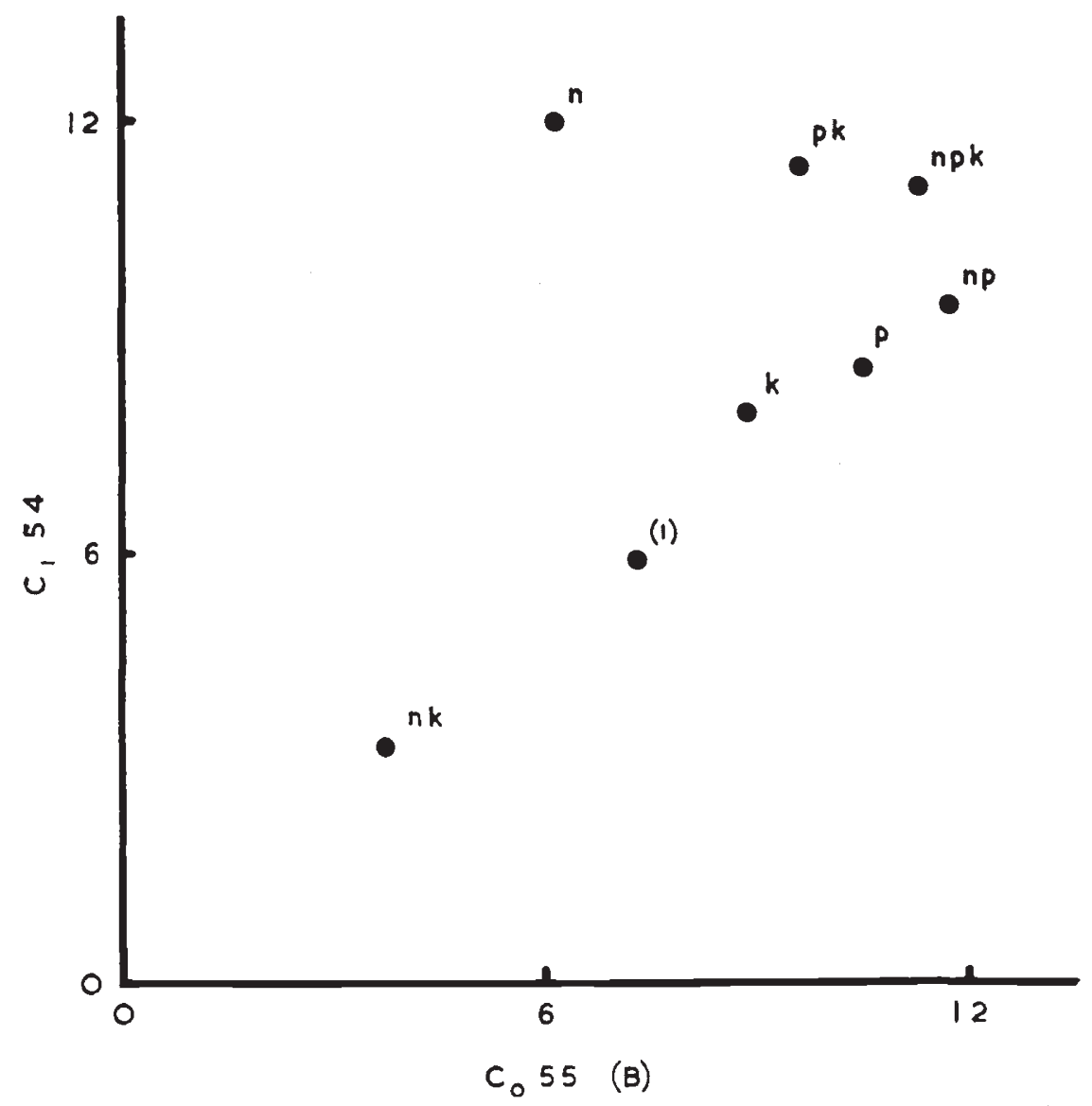

Fig. 1,-Comparison of $\mathrm{C}_{154}$ and $\mathrm{C}_{055}$ plant weights in the ist experiment.

greatest overall effect. Summing over the two levels of calcium and comparing the two sets of totals (table 2, column totals and row totals $B$ ) the npk plants are approximately three times the weight of the nk plants in both cases. Most of the $\mathrm{C}_{154}$ interactions are also highly significant, indicating that the balance of fertilisers applied to the parents is important. Inspection of fig. I shows that $\mathrm{C}_{154}$ and $\mathrm{C}_{0} 55$ (B) totals are fairly well correlated except for $\mathrm{n}$, the departure. of this treatment being mainly responsible for the non-significant correlation coefficient of $0 \cdot 5^{2}$. There is no doubt that there are real differences between the $\mathrm{C}_{154}$ totals comparable in magnitude to the differences produced by the direct application of fertilisers, $\mathrm{C}_{055}$. 
Table 3 shows that there is evidence of interaction between the plant weights of $\mathrm{C}_{154}$ and $\mathrm{C}_{055}$. To study this further, table 2 may be likened, after summing over the two levels of calcium, to a diallel table of crosses where the eight combinations of fertilisers are the eight genotypes, and $\mathrm{C}_{154}$ and $\mathrm{C}_{055}$ the male and female arrays respectively. The "homozygotes", or "selfs", are those plants

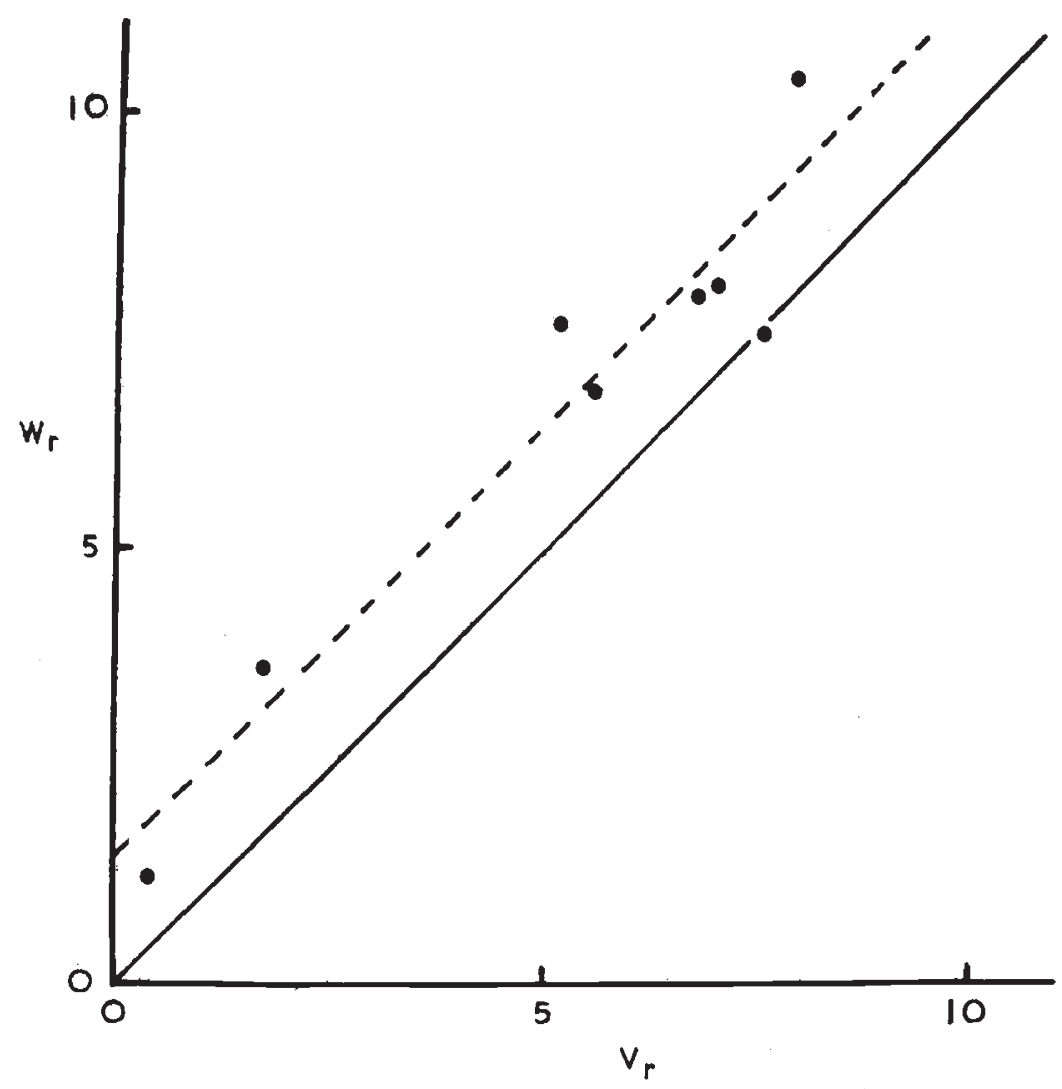

FIG. 2.-Covariance/variance graph of diallel analysis of $C_{154}$ and $C_{055}$ in the first experiment.

growing in the same environment as their parents, and the "heterozygotes", or " $F_{1} s$ ", those growing in different environments from their parents. If the plant weights of the " homozygotes" are greater, or less, than the "heterozygotes" then "dominance" acts in a negative, or positive, direction. Using the method of analysis of diallel tables of Jinks (1954), the regression of array covariances onto array variances shown in fig. 2 has a slope of 0.97 , and is highly significant. The correlation of $\mathrm{V}_{\mathrm{r}}+\mathrm{W}_{\mathrm{r}}$ with the "homozygotes" is positive $(r=0.85)$ and highly significant, so that "dominance", which is not complete, acts mainly in a negative direction. There is no evidence of any other form of interaction from this analysis which therefore means that plants on average have a greater weight when 
growing in the same environment as their parents. This is not due to adaptation to the environments, as would have been implied by ncgative "heterosis" had this occurred, but to the larger types responding more than the smaller types to higher soil fertility.

There are four alternative interpretations of these results.

1. There may be large residual genetic variability in the variety and chance assortment of the genetic factors among the groups of parent plants receiving the different treatments produced large phenotypic differences between the groups which are roughly correlated with the differences produced by the direct application of the respective fertilisers. This amount of variability was not evident in the parents and in the first generation the five plants within each plot were highly uniform.

TABLE 4

Mean seed weights (grams per rooo seed) in experiment I

\begin{tabular}{|c|c|c|c|c|c|c|c|c|c|}
\hline & $n p k$ & $n p$ & $n k$ & $n$ & $p k$ & $p$ & $k$ & $(\mathrm{r})$ & Total \\
\hline $\mathrm{C}_{0.54}$ & 3.8 & 3.6 & 3.3 & 3.9 & 4.3 & 4.2 & 4.1 & 3.8 & $31 \cdot 0$ \\
$\mathrm{C}_{154}$ & 5.5 & 5.4 & 5.4 & 5.7 & 5.7 & 5.6 & 5.4 & 5.5 & 44.2 \\
$\mathrm{C}_{0.55}$ & 5.5 & 5.6 & 5.4 & 5.5 & 5.6 & 5.5 & 5.5 & 5.6 & 44.2 \\
\hline
\end{tabular}

2. Large maternal effects may have been responsible. Judged by its weight, table 4, the seed collected in the damp I954 season from the treated parents, $\mathrm{C}_{054}$, was of poor quality, and the seed weights also varied between treatments, although they were not significantly correlated with the plant weights of the progeny. By comparison, seed collected in the sunny 1955 season from the ist generation plants, $\mathrm{C}_{154}$ and $\mathrm{C}_{055}$ combinations, was heavier and more uniform over the treatments, as shown by the overall means in table 4 .

3. The treatments may have had a selective action on residual genetic variability in the variety, the selection occurring at sporogenesis, fertilisation or seed setting, for genetic factors determining roughly the same plant weights as those produced by the respective treatments. To account for this, some precise, remarkable, and probably unconvincing mechanism would have to be postulated, as, for example, only those pollen grains carrying genetic factors for small plants survive, make faster growth down the style, or take part in fertilisation, in plants receiving nk.

4. The parental treatments may have induced heritable changes in the nucleus, cytoplasm, or in both. The ist and 2nd interpretations can be separated out by further experimentation, but the $3^{\text {rd }}$ and $4^{\text {th }}$ are less easily distinguished. At the sub-cellular level, selection for cytoplasmic particles, or an alteration in those particles, at any time 
during the parental generation would have the same nct effect, for both would result in an induced hcritable change.

Before passing on to the second generation somc other data recorded will be briefly mentioned, namely, flowering time, and growth in height, primarily for the purpose of comparing the effects of the two sets of treatments, $\mathrm{C}_{154}$ and $\mathrm{C}_{0} 55$. Flowering time was measured by the number of days after the 3oth June when the first flower opened on each plant. The mean flowering times per plant for $\mathrm{C}_{1} 54$, after summation over the $\mathrm{C}_{055}$ treatments, and the mean flowering times for $\mathrm{C}_{\mathbf{0}} 55$ after summation over $\mathrm{C}_{154}$, are given in table 5 . There is an overall difference of 16 days between the $\mathrm{C}_{0} 55$ treatments but only 3 days between the $\mathrm{C}_{154}$. treatments. The correlation between the two sets is negative $(\mathrm{r}=-0.3)$ and non-significant. Evidently there

TABLE 5

Mean flowering times of 80 plants. Days after the zoth June

\begin{tabular}{|c|c|c|c|c|c|c|c|c|c|}
\hline & $n p k$ & $n p$ & $n k$ & $n$ & $p k$ & $p$ & $k$ & $(1)$ & Total \\
\hline $\mathrm{C}_{154}$ & 9.9 & $8 \cdot 3$ & $7 \cdot 8$ & $10 \cdot 0$ & 9.0 & $8 \cdot 2$ & 8.2 & $7 \cdot 2$ & 68.6 \\
$\mathrm{C}_{055}$ & 0.2 & 1.9 & $15 \cdot 0$ & 16.0 & 2.5 & 6.2 & 12.6 & 14.2 & 68.6 \\
\hline
\end{tabular}

is no direct relationship between the two sets which not only makes it less likely that the first generation differences are due to the carry over of nutrients in the seed but also improbable that any differences occurring in the second generation (to be described) are due to transmission of hormones associated with the differences in flowering tinc of the first generation plants, since these differences are so small.

The heights of the plants were measured four times during growth and deviations due to the overall effects of the applications of $\mathrm{P}$ from the mean growth curve of all I 28 plants, calculated for $\mathrm{C}_{154}$ and $\mathrm{C}_{0} 55$ separately, are shown in fig. 3. Deviations for plants not receiving phosphorus give mirror images on the other side of the $\mathrm{X}$ axis and are omitted. The deviation due to $\mathrm{C}_{154} \mathrm{P}$ is small, and the curve is inverted compared with that of $\mathrm{C}_{0} 55 \mathrm{P}$, giving additional evidence for a real difference in the growth characteristics of the two sets.

\section{(iii) The second generation-study of the progeny of $C_{1} 54$ nk and $C_{1} 54$ npk in 1956}

Seed taken from the first generation plants in I955 (table 2) was used for studies on the second generation in 1956. The purpose of the first to be described was to determine whether the difference between two extreme types in the first generation, $\mathrm{C}_{154 \mathrm{npk}}$ and $\mathrm{C}_{154} \mathrm{nk}$, reappeared in the second generation, $\mathrm{C}_{254 \mathrm{npk}}$ and $\mathrm{C}_{254 \mathrm{nk}}$, and/or whether the two types responded to the 16 combinations of treatments in which they were grown in $1955\left(\mathrm{C}_{055}\right)$ to produce a 
further range of types in the following generation $\left(\mathrm{C}_{155}\right)$. The 32 combinations (two $\mathrm{C}_{254} \times$ sixteen $\mathrm{C}_{155}$ ) were grown in boxes and field plots receiving eight combinations of treatments $\left(\mathrm{C}_{05} 6\right)$, npkg, $\mathrm{npk}, \mathrm{npg}, \mathrm{np}, \mathrm{pkg}, \mathrm{pk}, \mathrm{pg}, \mathrm{p}$, replicated twicc. The $4^{\text {th }}$ order interaction, $\mathrm{C}_{254} / \mathrm{C}_{15} \mathrm{~N} / \mathrm{P} / \mathrm{K} / \mathrm{G}$, was confounded between the replications of the $\mathrm{C}_{05} 5$ box and field treatments so that there were only ${ }_{1} 6$ of the $3^{2}$ combinations of $\mathrm{C}_{254}$ and $\mathrm{C}_{155}$ in any one field plot, and in any

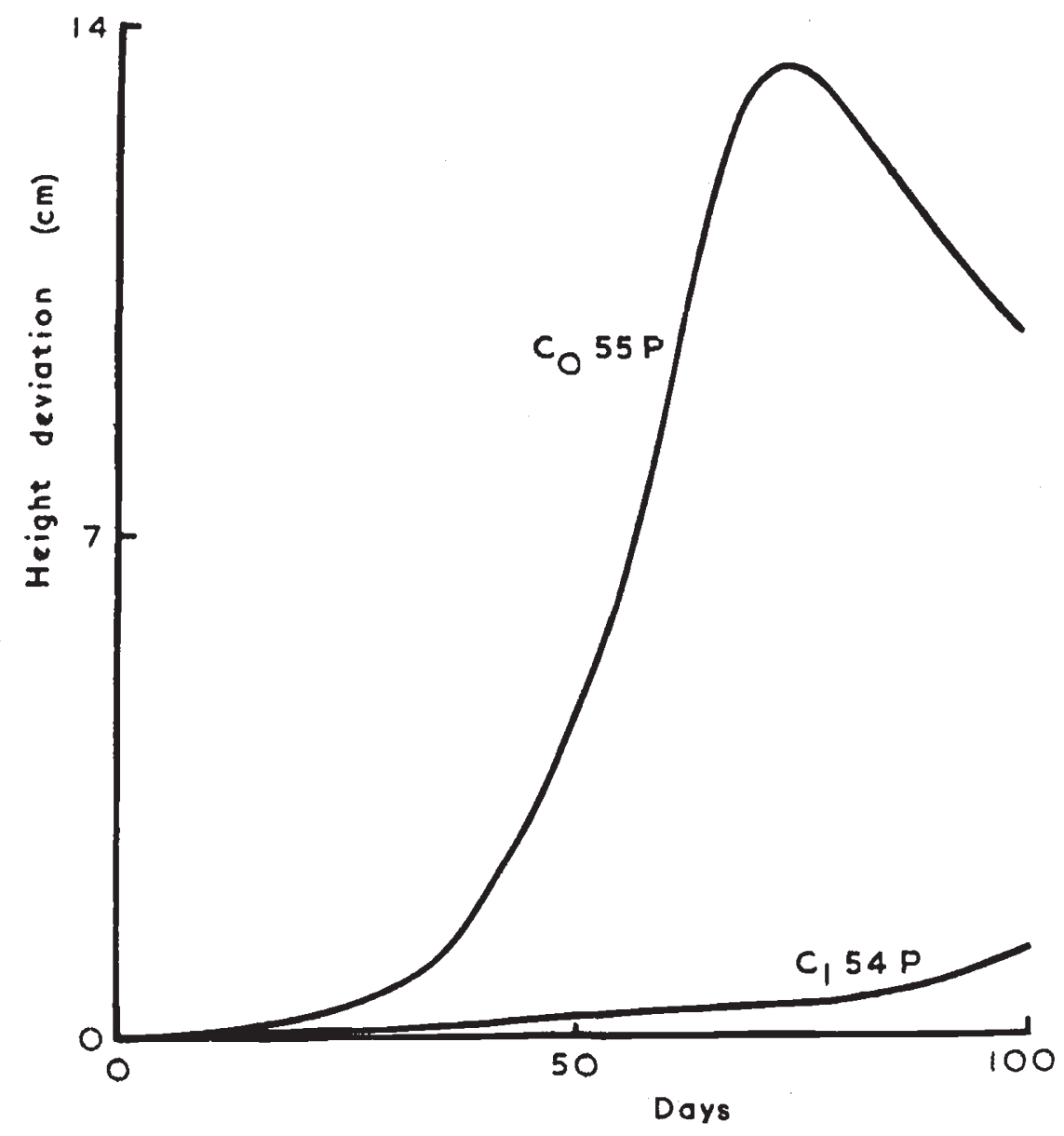

Fig. 3.-Deviations from the mean growth curve of $\mathrm{C}_{154} \mathrm{P}$ and $\mathrm{C}_{05} \mathrm{P}$.

one group of boxes in each replicate receiving the same $\mathrm{C}_{05} 6$ treatment. As before there were five plants in each row, giving 1280 plants in all.

The mean weights of the plants, after summing over the eight $\mathrm{C}_{05} 6$ treatments, the two replications and the two levels of lime of $\mathrm{C}_{155}$, are given in table $6 . \mathrm{C}_{2} 54^{\mathrm{npk}}$ is about three times greater than $\mathrm{C}_{2} 54^{\text {nk }}$ for all $\mathrm{C}_{1} 55^{\mathrm{npk}} \ldots$.. (I), giving no evidence that the difference between $\mathrm{C}_{154}$ nk and $\mathrm{C}_{154 \mathrm{npk}}$ has diminished in the 2nd generation, even though the seed collected from the ist generation plants in 1955 was uniform and of good quality (table 4 ). 
In contrast, the transmitted effects of the fertilisers $\mathrm{C}_{0} 55^{\mathrm{npk}} \ldots$.. ( $\mathrm{I}$ ), which were applied in 1955 to the two extreme types, $\mathrm{C}_{154 \mathrm{npk}}$ and $\mathrm{C}_{154 \mathrm{nk}}$, of the Ist generation plants of the 1954 treatments, to the Ist generation, $\mathrm{C}_{155} \mathrm{npk} \ldots(\mathrm{I})$, are small. The extreme types were

TABLE 6

Plant weights (oz.): means of 80 plants

\begin{tabular}{|c|c|c|c|c|c|c|c|c|c|}
\hline & \multicolumn{8}{|c|}{$\mathrm{C}_{155}$} & \multirow{2}{*}{ Total } \\
\hline & npk & np & $\mathrm{nk}$ & $\mathrm{n}$ & $\mathrm{pk}$ & $\mathrm{p}$ & k & (i) & \\
\hline 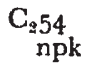 & $5 \cdot 6$ & 5.9 & $5 \cdot 7$ & 57 & 5.7 & $5 \cdot 6$ & $6 \cdot I$ & 5.7 & $4^{6 \cdot 0}$ \\
\hline nk & $2 \cdot 3$ & I. 8 & $1 \cdot 6$ & $1 \cdot 6$ & $2 \cdot 5$ & $1 \cdot 9$ & I.6 & I.6 & 14.9 \\
\hline
\end{tabular}

analysed separately because they had different error variabilities. The $\mathrm{C}_{155}$ means within $\mathrm{C}_{25}$ npk were not significantly different. The analysis of the $\mathrm{C}_{155}$ within $\mathrm{C}_{\mathbf{2}} 54^{\mathrm{nk}}$ is given in table 7 where the data has been split down sufficient to show that highly significant

TABLE 7

Analysis of variance of $C_{155}$ within $C_{25}$ nk of table 6

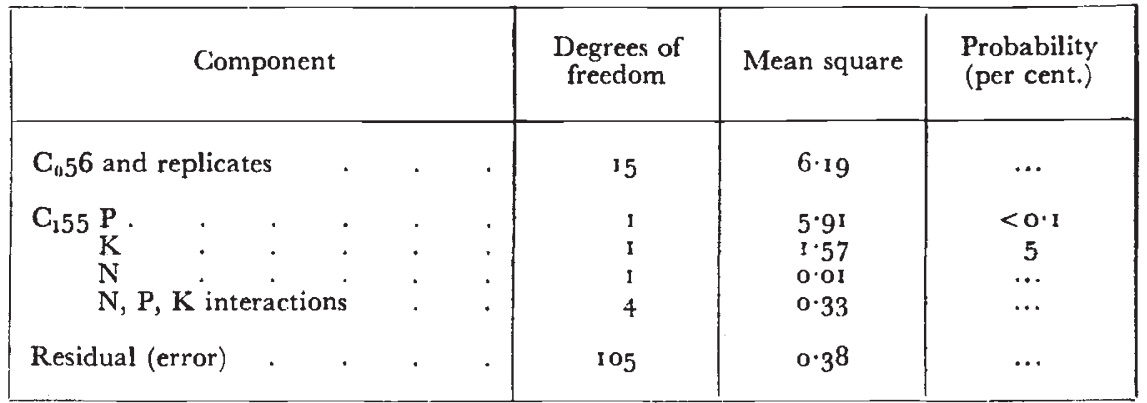

differences occur, presumably due to the transmitted effects of the I955 treatments where, as before, phosphorus has the greatest overall effect. On the other hand, the correlation of the $\mathrm{C}_{155}$ means within $\mathrm{C}_{254 \mathrm{nk}}$ with the $\mathrm{C}_{055}$ treatment totals summed over all the plants (table 2, totals $\mathrm{B})$ is low $(\mathrm{r}=0.36)$, and practically zero with their parental weights (table 2, nk column). The results of the I954 treatments are not repeated for, unlike these, the large differences produced by the 1955 treatments do not reappear in the next generation and such differences that do appear, 45 per cent. at the most, could reasonably be ascribed to maternal effects. 
(iv) The second generation-study of all progeny in 1956

In 1956 , the progeny of all 128 combinations of $\mathrm{C}_{154}$ and $\mathrm{C}_{0} 55$ grown in 1955 (see table 2) were replicated four times in npkg plots.

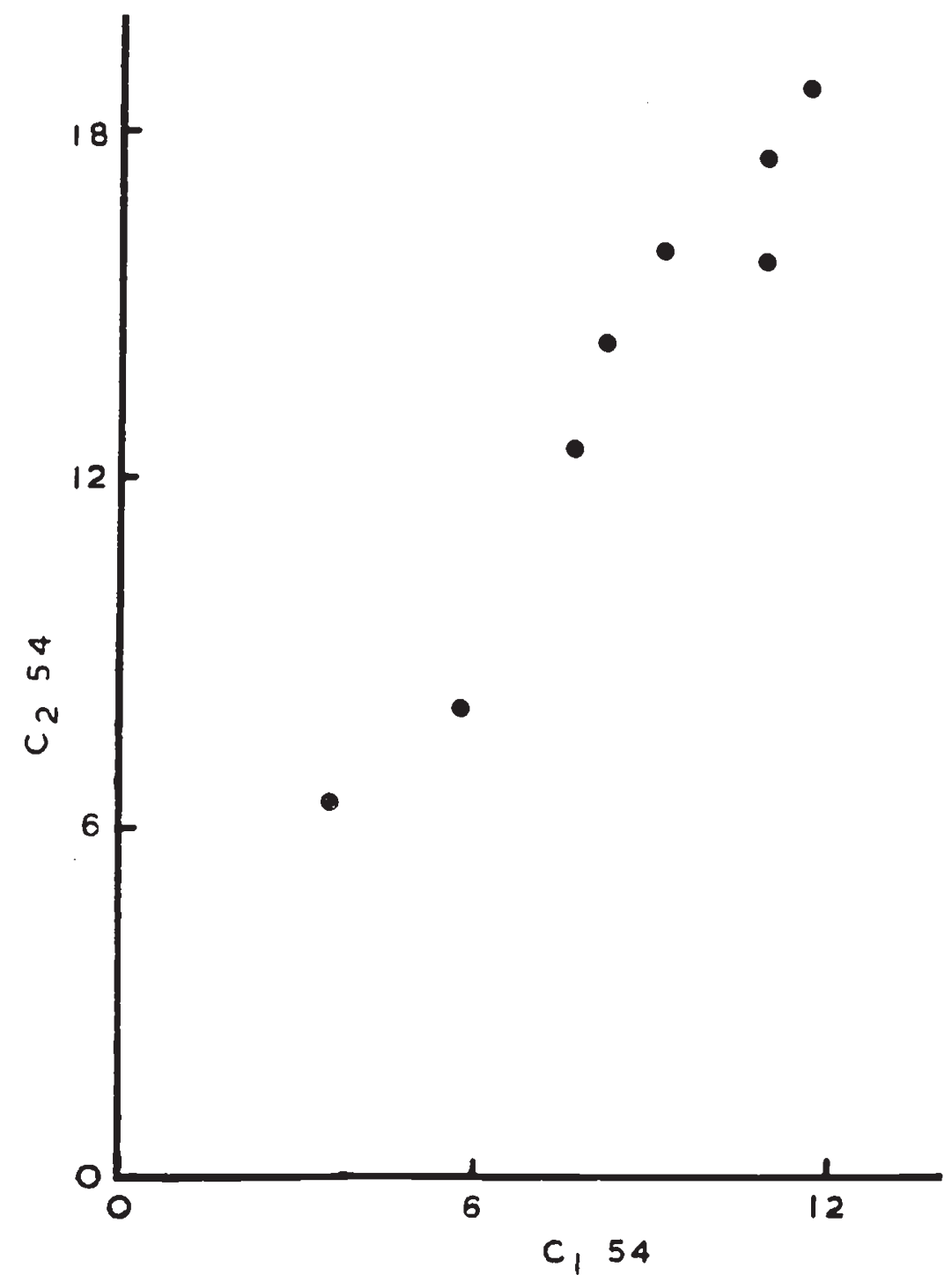

FIc. 4.-Comparison of $\mathrm{C}_{254}$ (2nd generation) and $\mathrm{C}_{2.54}$ (Ist generation). Weights (lb.) of 80 plants.

I.osses were too large in the first two replicates, due to drought at transplanting, to warrant cutting and weighing. There were fewer losses in the remaining two replicatcs, the transplanting of which had been postponcd, but sufficient to make detailed analysis not worth while, so that means only are shown in fig. 4 where $\mathrm{C}_{2} 54$ mean 
plant weights obtained after summing over $\mathrm{C}_{1} 55$ are plotted against the mean plant weights obtained in 1955 for $C_{155}$ after summing over $\mathrm{C}_{055}$. This figure, comparing the Ist and 2nd generations of the $\mathrm{C}_{054}$ treatments, shows that the correlation between them is virtually complete $(r=0.97)$ and the differences have not diminished in the second generation. This result cannot be due to selection occurring in this $\mathrm{C}_{2}$ where there were large losses, for the same result was given by the extreme types, npk and $n k$, in the previously described $\mathrm{C}_{2}$ plants where no losses occurred. $\mathrm{C}_{155}$ mean plant weights obtained after summing over $\mathrm{C}_{2} 54$ differed by small amounts, but gave little indication of any transmitted response from the $\mathrm{C}_{055}$ plants.

These two 1956 2nd generation studies show that differences similar to those in the first generation of the 1954 treatments were not obtained in the first generation of the 1955 treatments, yet the first generation differences of the 1954 treatments are transmitted undiminished to the second generation. Therefore the most plausible explanation of the differences in the first and second generations of the 1954 treatments is chance assortment of genetic factors and not environmentally induced heritable change, nor maternal inheritance, despite the magnitude of the differences, the uniformity of the plants and a suggestive correlation between the direct and transmitted responses to the fertiliser treatments. On the other hand, this may be an unwarranted conclusion because in the first place the treatments were applied, and the first generations were grown, in different seasons, and seasonal factors may be as important as nutritional factors. Secondly, if the 1954 treatments had induced heritable changes then the plants which leceived the I 955 treatments must be "genetically" and physiologically different from those which received the 1956 treatments and they need not necessarily respond in the same way.

\section{Experiment 2-Treatments applied in 1956: parents, 1 st and 2nd generations}

In 1956 , seed was taken from the same sample used for the r 954 treatments and Io plants were grown in each of the eight fertiliser treatments, npkg, npk, nkg, nk, pg, p, g (I). Table 8 shows that there are large differences in the first generation which are similar, although not identical, with the first generation of the respective I954 treatments. Phosphorus applied by itself now has the same effect as nk, producing a small type of plant, and only when lime is applied with phosphorus, and to a certain extent with npk, is the large type produced in the next generation. Table 8 also shows that the progeny are not necessarily correlated in weight with their parents, $p$ giving a large parent plant but a small ist generation plant, and in the three cases where the second generation was grown the effects are transmitted to this generation as well. The discrepancies between these results and those obtained following the I954 treatments are 
probably due to the overall decrease in soil fertility, particularly in nitrogen and lime.

This experiment demonstrates that differences are again obtained in the first and second generations when the original stock of seed is used. Larger and more profitably designed experiments will be described later which will demonstrate that the failure of the 1955

TABLE 8

Mean plant weights $(\mathrm{g})$ of treated parents in 1956 and their progeny

\begin{tabular}{|c|c|c|c|c|c|c|c|c|c|}
\hline & \multicolumn{7}{|c|}{ Treatments } & $\begin{array}{c}\text { No. of plants } \\
\text { per treatment }\end{array}$ \\
\cline { 2 - 8 } & npkg & npk & nkg & $\mathrm{nk}$ & $\mathrm{pg}$ & $\mathrm{p}$ & $\mathrm{g}$ & $(1)$ & \\
\hline $\mathrm{C}_{05} 6$ & 62 & 38 & 3 & 1 & 65 & 58 & 40 & 30 & 10 \\
$\mathrm{C}_{156}$ & 56 & 42 & 34 & 23 & 58 & 20 & 27 & 31 & 30 \\
$\mathrm{C}_{25} 6$ & 60 & $\ldots$ & $\ldots$ & 24 & $\ldots$ & 22 & $\ldots$ & $\ldots$ & 20 \\
\hline
\end{tabular}

treatments to produce differences in the first generation was primarily due to the type of plant used, although other factors play a part. It will be convenient to consider first some characteristics of two extreme types, npk and nk, noting from the foregoing that their origin cannot be reasonably ascribed to chance assortment of genetic factors, nor to maternal inheritance.

\section{CHARACTERISTICS OF TWO EXTREME TYPES}

\section{Experiment 3-Stability}

The progeny of two extreme types, npk and nk, arising from the I954 fertiliser applications were grown for several generations in

TABLE 9

Mean plant weights (oz.) of descendants of plants receiving $n$ pk and $n k$ in 1954

\begin{tabular}{|c|c|c|c|c|}
\hline \multirow{3}{*}{ Generation } & \multirow{2}{*}{$\begin{array}{c}\text { Year } \\
\text { grown }\end{array}$} & \multicolumn{2}{|c|}{ Treatment } & \multirow{2}{*}{$\begin{array}{c}\text { No. of plants } \\
\text { cach }\end{array}$} \\
\cline { 3 - 5 } & & $\mathrm{npk}$ & $\mathrm{nk}$ & \\
\hline & & & & \\
\hline 1 & 1955 & 2.2 & 0.7 & 80 \\
2 & 1956 & 3.5 & 1.3 & 40 \\
3 & 1957 & 2.9 & 0.8 & 40 \\
4 & 1958 & 3.5 & 1.2 & 40 \\
5 & 1959 & 2.9 & 0.8 & 40 \\
6 & 1960 & 1.7 & 0.6 & 40 \\
\hline
\end{tabular}

soil to which had been applied lime and N, P and $\mathrm{K}$ or a compound fertiliser. Table 9 shows that the npk plants remained about three 
times the weight of the nk plants, and up to the 6th generation there is no sign of this difference diminishing. The two types have been grown in other fertilisers with the same result. Attempts to reverse them by growing the npk plants in nk and the nk plants in npk produced only small, and somewhat erratic, deviations in the following generation similar to those already described (see table 6).

Within the types, npk and nk, the plants are extremely uniform. Table Io gives examples taken from three blocks of an experiment containing, among others, npk and nk plots with eight plants in each plot. As previously mentioned, seed for sowing is taken from at least five plants and bulked so that there is no question of the uniformity being due to the establishment of a type from a single homozygous

TABLE 10

Weights (g.) of individual $n p k$ and $n k$ plants

\begin{tabular}{|c|c|c|c|c|c|c|c|c|c|}
\hline \multirow{3}{*}{ Block 1 } & $\mathrm{npk}$ & 34 & 39 & 49 & 39 & 32 & 33 & 35 & 40 \\
\cline { 2 - 7 } & $\mathrm{nk}$ & 10 & 14 & 13 & 11 & 12 & 11 & 15 & 14 \\
\hline \multirow{3}{*}{ Block 2 } & $\mathrm{npk}$ & 39 & 45 & 41 & 45 & 38 & 35 & 34 & 34 \\
\hline & $\mathrm{nk}$ & 19 & 15 & 11 & 10 & 12 & 10 & 11 & 13 \\
\hline \multirow{3}{*}{ Block 3 } & $\mathrm{npk}$ & 54 & 45 & 54 & 49 & 51 & 54 & 41 & 46 \\
\hline & $\mathrm{nk}$ & 31 & 10 & 11 & 6 & 15 & 7 & 9 & 8 \\
\hline
\end{tabular}

individual. Plate $\mathrm{I}$ shows the two extreme types. The differences are similar to those which would normally, although not necessarily, be expected from genetic factors determining quantitative variation. There are no differences in flower colour, leaf shape or other morphological characters of this type.

\section{Experiment 4-Grafts}

Reciprocal grafts were made between the npk and nk plants and also between npk plants and between nk plants in 1957 . They were 3 rd generation plants of the 1954 treatments which had been grown in npkg in the Ist and 2nd generations. For these experiments they were grown in compost in pots to which was added npkg. The grafts were made in the following manner. When the plants were about three weeks old the stock was prepared by removing the upper part of the plant just above the attachment of the cotyledenous leaves and making a longitudinal slit about half an inch long in the stem between the cotyledenous leaves, taking care not to damage these or the small axillary buds. The scion was prepared from the terminal $I \frac{1}{4}$ inches of the young plant, the lower portion of which was cut into a wedge. shape after the removal of the leaves in this region, and inserted into 
the stock. The join was bound with cotton, and surrounded with moist peat. They were left for two weeks, during which any roots appearing from the scion were immediately rubbed off, and then the cotton and peat was removed. The scion of the mature plant consisted solely of the central, terminal shoot and the stock included the side branches which arose from the axillary buds of the cotyledenous leaves.

TABLE I I

Mean weights (g.) of stock and scion of grafts made with $n p k$ and $n k$

\begin{tabular}{|c|c|c|c|c|c|}
\hline \multicolumn{2}{|c|}{ Stock } & \multicolumn{2}{c|}{ Scion } & $\begin{array}{c}\text { Total } \\
\text { weight }\end{array}$ & $\begin{array}{c}\text { No. of } \\
\text { plants }\end{array}$ \\
\hline Type & Weight & Type & Weight & & \\
\hline npk & 48 & npk & 23 & 71 & 19 \\
npk & 62 & nk & 10 & 72 & 21 \\
nk & 37 & npk & 22 & 59 & 22 \\
nk & 43 & nk & 9 & 52 & 18 \\
\hline
\end{tabular}

Table I I shows that the stock has no effect on the scion. The npk scion weighs about 22 grams on both stocks, and the nk scion weighs about 9 grams on both stocks. The stock itself is affected by the scion but in a direction expected from the normal physiological response of side branching to terminal shoot growth. The totals show that the overall plant weight is determined mainly by the stock.

TABLE 12

Mcan plant weights (g.) of 30 plants of the progeny of stock and scion of grafts made with $n p k$ and $n k$

\begin{tabular}{|l|c|c|c|c|}
\hline \multicolumn{2}{|c|}{ Progeny of stock } & \multicolumn{2}{|c|}{ Progeny of scion } & \multirow{2}{*}{ Total } \\
\hline Type & Weight & Type & W'eight & \\
\hline npk & 84 & $n p k$ & 79 & 163 \\
npk & 76 & $n k$ & 14 & 90 \\
nk & 13 & $n p k$ & 76 & 89 \\
nk & 14 & $n k$ & 15 & 29 \\
\hline
\end{tabular}

Seed taken from the stock and scion of 6 plants of each of the four types of graft was sown the following year in compound fertiliser. Table I 2 shows that in all cases plants are produced showing the same characteristic difference in weight as occurs between ungrafted npk and nk plants. There are relatively small deviations, but they are not consistently in directions that would be expected had the stock influenced the scion, and vice versa. The difference between npk 
and $n k$ is greater in the progeny of the grafts than in the grafts themselves, which is clue to the mutilation in preparation, and pot culture, of the grafts. There is no evidence that the factors determining the difference between the two types are graft transmitted and therefore they cannot be nutritional nor hormonal.

\section{Experiment 5-Crosses}

Crosses were made between npk plants, between nk plants, and reciprocally between npk and nk plants, in 1956, 1957 and $195^{8}$. The plants crossed were the 2nd, $3^{\text {rd }}$ and $4^{\text {th }}$ generation plants respectively of the $1954 \mathrm{npk}$ and nk treatments which had been grown in the intervening generations in npkg. Plants used for crossing in 1956 were grown in their respective treatments of $\mathrm{npk}$ and $\mathrm{nk}$, and those used for crossing in 1957 and $195^{8}$ were grown with npk compound fertiliser and lime. In each case the first generation of the

\section{TABLE 13}

Mean plant weights (g.) of crosses between $n p k$ and $n k$ types in three experiments. Least cignificant difference ( 5 per cent.) between overall means of 75 plants each $=7 \cdot 0$

\begin{tabular}{|c|c|c|c|c|}
\hline & $n p k \times n p k$ & $n p k \times n k$ & $n k \times n p k$ & $n k \times n k$ \\
\hline Experiment (i) & 62 & 40 & 30 & 13 \\
Experiment (ii) & 22 & 15 & 16 & 6 \\
Experiment (iii) & 64 & 49 & 51 & 17 \\
Oicrall means & 49 & 35 & 32 & 12 \\
\hline
\end{tabular}

crosses was grown the following year in npk compound fertiliser with lime. The plant weights are given in table $\mathrm{I}_{3}$.

The reciprocal crosses of npk and nk are virtually identical in weight so the factors responsible for the difference between npk and $\mathrm{nk}$ are transmitted equally by the male and female gametes and the nucleus may therefore be involved. If they were solely cytoplasmic and transmitted through the pollen they would not necessarily give equilinear inheritance.

These studies on the stability of the two types, npk and nk, and on their graft progeny and crossing, show that they are quite distinct and they behave in a manner similar to different genetic types. The experiments give no direct support to maternal inheritance, but taken by themselves, they could equally be taken as confirmation of their origin from the assortment of genetic factors as from environmentally induced heritable change. This will be considered in more detail below.

\section{DIFFERENTIATION OF PLANTS}

Evidence was presented earlier for supposing that differences in plant weights occurring among the descendents of plants receiving 
different fertiliser treatments were due to the direct effect of the fertilisers. Tro extreme types which have arisen in this manner were quite stable in the different environments in which they were grown. Confirmatory experiments (experiments 6 to ro, below) will be

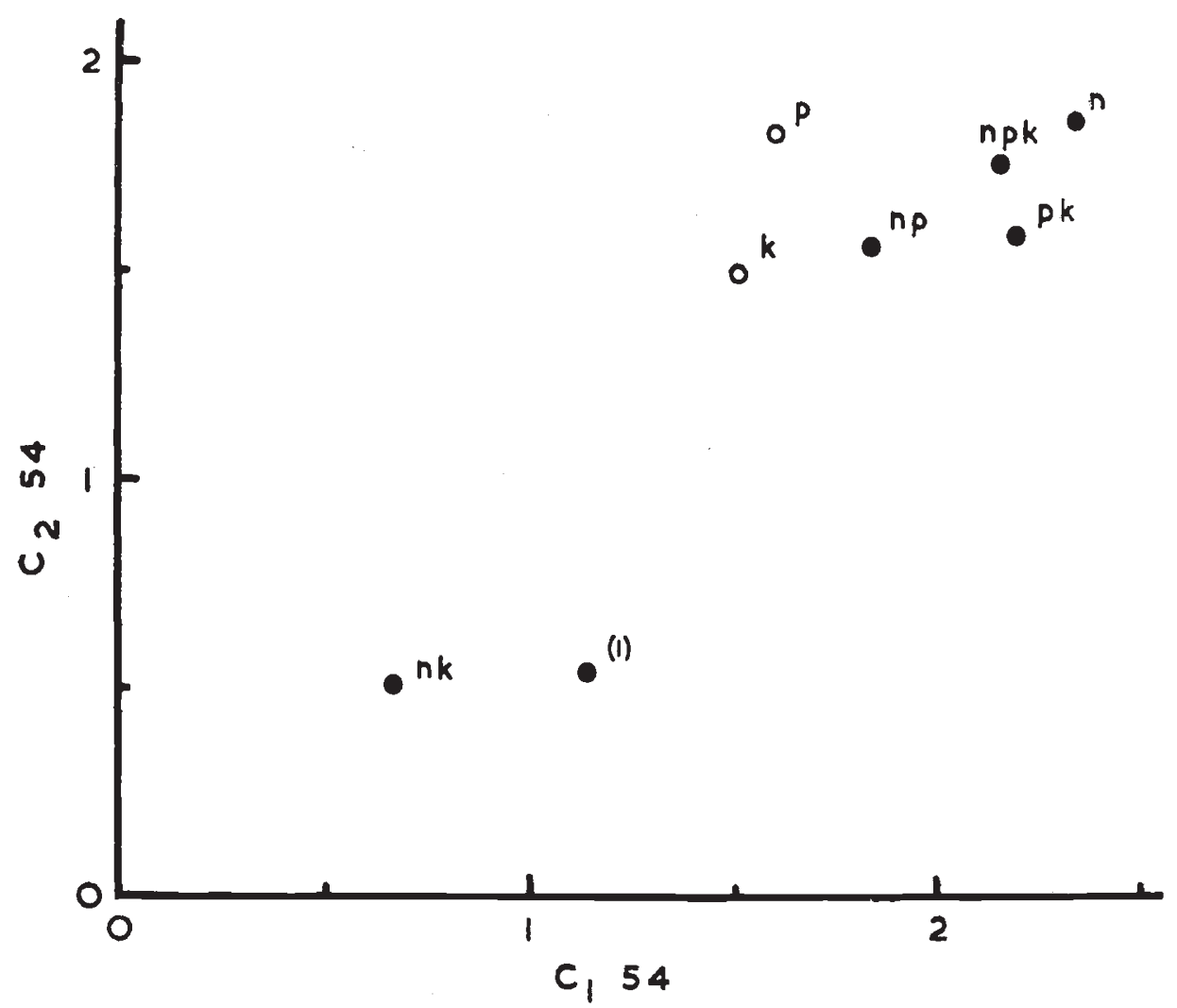

Frg. 5A.-Comparison of mean plant weights (oz.) of $\mathrm{C}_{254}$ progeny of $\mathrm{C}_{154}$ plants grown in npk and npkg, and $\mathrm{C}_{154}$ (column totals, table 2).

described which will also throw further light on the circumstances of the effectiveness of the fertilisers in producing changes in some cases, but not in others.

\section{Experiment 6-Induction tests on $C_{1} 54$ types}

The purpose of this experiment was to establish whether any of the eight $\mathrm{C}_{154}$ types had the capacity to change, or whether they were all as unresponsive as the two extremes, $\mathrm{C}_{154} \mathrm{npk}$ and $\mathrm{C}_{1} 54 \mathrm{nk}$, already studied (table 6). Second generation plants of the eight $\mathrm{C}_{054}$ parental treatments, whose first generation had been grown in the $\mathrm{C}_{0} 55$ treatments of npkg, npk, $g$ and (I), were grown in 1957 in compound fertiliser with lime. These plants are therefore combinations of $\mathrm{C}_{254}$ and $\mathrm{C}_{155}$. There were four replicates each containing four blocks consisting of the four $\mathrm{C}_{155}$ types sub-divided into eight piots 
consisting of the eight $\mathrm{C}_{25} 4$ types. There were five plants per plot giving 640 plants in all.

The weights of $\mathrm{C}_{254}$ after passage in the previous generation through npkg and npk taken together, and after passage through $\mathrm{g}$

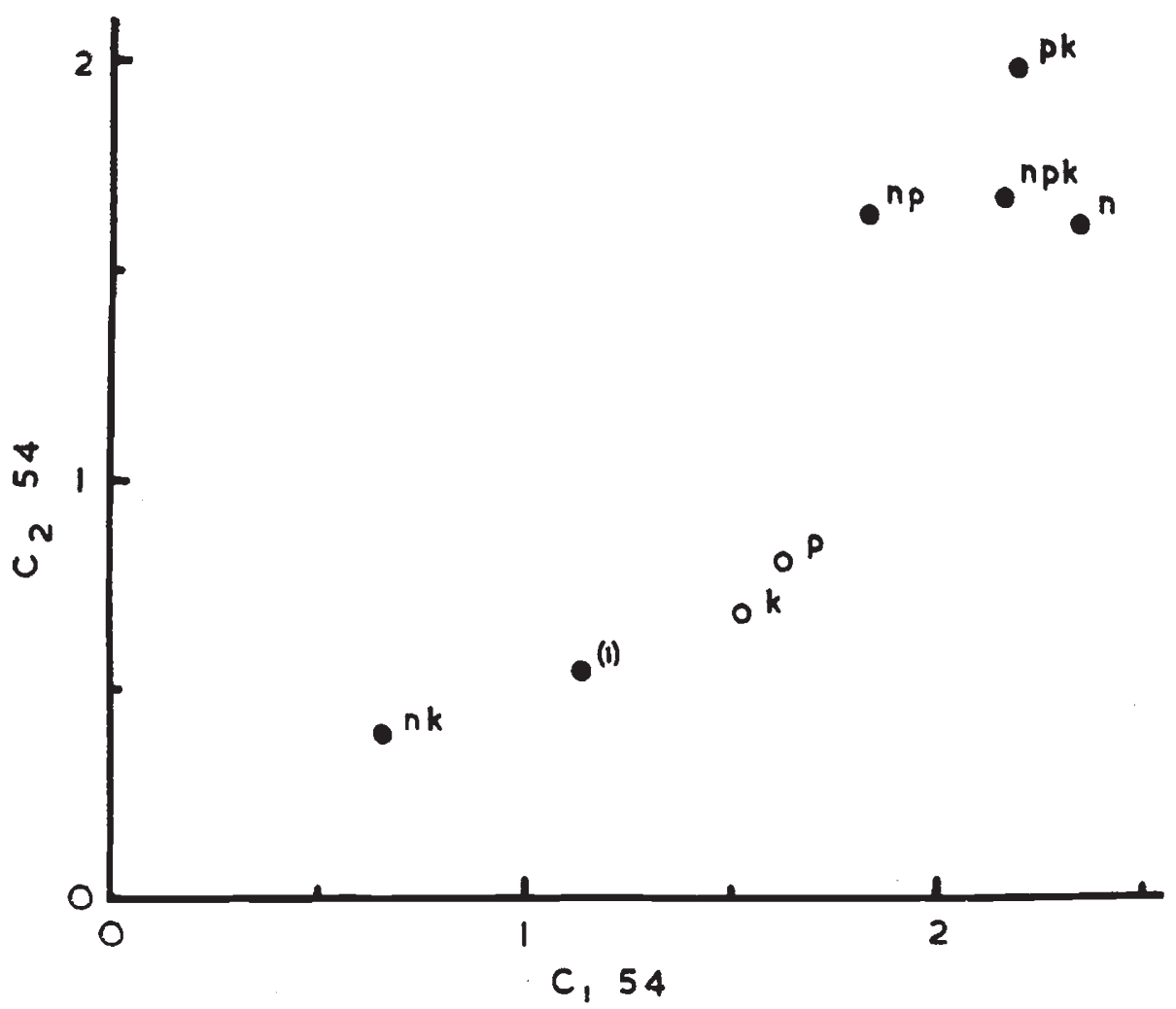

FIG. 5B.-Comparison of mean plant weights (oz.) of $\mathrm{C}_{254}$ progeny of $\mathrm{C}_{154}$ plants grown in $g$ and ( $\mathrm{l}$ ), and $\mathrm{C}_{154}$ (column totals, table 2 ).

and (I) taken together, are plotted against the overall weights of $\mathrm{C}_{154}$ (column totals, table 2 ) in figs. $5^{\mathrm{A}}$ and $5^{\mathrm{B}}$ respectively. If all eight $\mathrm{C}_{1} 54$ types are as stable as the two extremes, npk and nk, then there should be a constant relationship between $\mathrm{C}_{154}$ and $\mathrm{C}_{254}$ irrespective of whether $\mathrm{C}_{154}$ was grown in $n p k g, n p k, g$ or (I). There is a reasonable correlation in both figures, confirming the transmission of the $\mathrm{C}_{054}$ treatment effects to the second generation, but in each case therc arc two types, $\mathrm{p}$ and $\mathrm{k}$, which are mainly responsible for diminishing the fit to a linear regression line. After passage through npkg and $n p k$ in the first gencration, $\mathrm{C}_{254} \mathrm{p}$ and $\mathrm{C}_{254 \mathrm{k}}$ plants are large, and after passage through $\mathrm{g}$ and ( $\mathrm{I}$ ) they are small, in relation to the others. In the first case they have approximately the same wcight as $\mathrm{C}_{254 \mathrm{npk}}$ and in the second they approach $\mathrm{C}_{254}(\mathrm{r})$ in ivcight. The conclusion is that $\mathrm{C}_{154 \mathrm{p}}$ and $\mathrm{C}_{15} 54 \mathrm{k}$ are the only two types among the $\mathrm{C}_{154}$ set in which heritable changes can be induced. 
It is unlikely that these results have arisen by chance for the movements of both $\mathrm{p}$ and $\mathrm{k}$ in response to both combined $\mathrm{C}_{055}$ treatments are in directions expected from the $\mathrm{C}_{055}$ treatments.

Referring to table 2, the mean of the weights of the two extremes among the $\mathrm{C}_{154}$ types (column totals, $\mathrm{nk}=\mathrm{II} \cdot 8, \mathrm{n}=38.7$ which approximates closely to $\mathrm{npk}$ ) is $25 \cdot 25$. The values for $\mathrm{C}_{154 \mathrm{p}}$ and $\mathrm{C}_{1} 54 \mathrm{k}$ are 26.8 and 25.5 respectively. Thus the two types in which presumed heritable changes have been induced have weights midway between the extreme types. $\mathrm{C}_{154 \mathrm{p}}$ and $\mathrm{C}_{154 \mathrm{k}}$ will be referred to as plastic types to distinguish them from the other $\mathrm{C}_{154}$ types which are stable as far as it has been shown up to the present.

\section{Experiment 7-Induction tests on four $C_{1} 54$ types}

This was similar to experiment 6 except that it was designed to study the responses of four $\mathrm{C}_{154}$ types, npk, nk, p, ( 1 ), to four $\mathrm{C}_{055}$ treatments $n p k, n k, p$ and ( 1 ) (see table 2). The progeny were grown in 1957 and consisted of the 16 combinations of the four $\mathrm{C}_{254}$ and the four $\mathrm{C}_{155}$ types. The weights given in table 14 are the totals of

TABI.E 14

Mean plant weights $(g$.$) of 10$ plants. Least significant difference ( 5 per cent.) for row and column totals $=45 . \mathrm{I}$

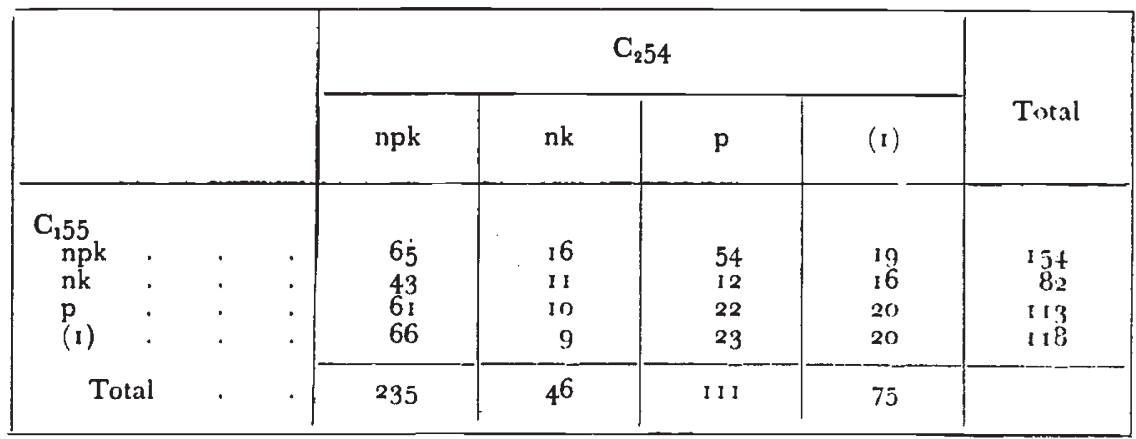

two replicates only, one grown in npkg and the other in pg (losses in other rcplicates due to drought at transplanting were too great to warrant their inclusion) so that the experiment is not particularly sensitive. The differences between the $\mathrm{C}_{254}$ totals are highly significant which is in agreement with the results of several previously described experiments. The $\mathrm{C}_{155}$ totals arc significant at the 5 per cent. level only and the intcractions betwcen $\mathrm{C}_{254}$ and $\mathrm{C}_{155}$ arc not significant. The $\mathrm{C}_{155}$ differences are in the same direction as those given in table 8 , or similar to the $\mathrm{C}_{254}$ totals here. The biggest differences in $\mathrm{C}_{1} 55$ occur among the $\mathrm{C}_{2} 54 \mathrm{p}$ plants. The percentage increase of $\mathrm{C}_{155} \mathrm{npk}$ over $\mathrm{C}_{155 \mathrm{nk}}$ for $\mathrm{C}_{2} 54 \mathrm{p}$ is $34 \mathrm{O}$, compared with 50,40 and

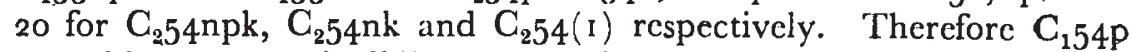
was able to transmit differences to the next generation following the 
$\mathrm{C}_{055}$ treatments, and the others hardly at all, in confirmation of Experiment 6.

\section{Experiment 8-Induction tests on two $C_{1} 54$ types}

Experiments 6 and 7 agreed in showing that of the $C_{154}$ types, $p$, but not npk, nk or ( $\mathrm{I}$ ), was capable of transmitting responscs to fertiliscrs to the next generation. Experiment 6 showed that $\mathrm{C}_{154} \mathrm{k}$ also had this property, and this was tested again, with $\mathrm{C}_{1} 54 \mathrm{pk}$ for comparison. The progeny were grown in npk compound fertiliser with lime in 1959, the same $\mathrm{C}_{055}$ treatments being used as in Experiment 7 . $\mathrm{C}_{254} \mathrm{k}$ and $\mathrm{C}_{254 \mathrm{pk}}$ were placed in separate blocks each consisting of eight replications containing the four $\mathrm{C}_{155}$ types. The plant weights are given in table 15 . The differences between the $\mathrm{C}_{155}$

TABI.E 15

Mean plant weights $(g$.$) of 40$ plants. Least significant difference ( 5 per cent. for $C_{25} 5 k=-4 \cdot 6$

\begin{tabular}{|c|c|c|c|c|}
\hline & \multicolumn{4}{|c|}{$C_{155}$} \\
\hline & npk & nk & $\mathrm{p}$ & (1) \\
\hline $\mathrm{C}_{254 \mathrm{k}}$ & 49 & 16 & 16 & 24 \\
\hline $\mathrm{C}_{254 \mathrm{pk}}$ & 39 & 41 & 45 & 42 \\
\hline
\end{tabular}

weights are highly significant $\left(\mathrm{P}<\mathrm{O}^{\cdot} \cdot \mathrm{I}\right.$ per cent.) for $\mathrm{C}_{254 \mathrm{k}}$, but not significant for $\mathrm{C}_{2} 54 \mathrm{pk}$, confirming the plasticity of $\mathrm{C}_{154 \mathrm{k}}$ and the stability of $\mathrm{C}_{154 \mathrm{pk}}$. The differences between the $\mathrm{C}_{155}$ plant weights of $\mathrm{C}_{254} \mathrm{k}$ are in the same directions as those between the $\mathrm{C}_{155}$ plant weights of $\mathrm{C}_{254 \mathrm{p}}$ in table 14 and between the appropriate means in table 8. These are three independent cxpcriments giving results similar to those of the initial 1954 experiment, except that on averagc $p$ now induces a small rather than an intermediatc plant.

\section{Experiment 9-Nutritional lines}

Sixteen lincs have been maintained by growing plants in the same fertilisers for a number of years. These are called nutritional lines. They were descended from the plants which received the eight $\mathrm{C}_{054}$ treatments, but the eight $\mathrm{C}_{154}$ types which were grown respectively in the eight $\mathrm{C}_{055}$ treatments were split into two, with lime, and without lime, so that thereon there were nutritional lines of all sixteen combinations of $\mathrm{N}, \mathrm{P}, \mathrm{K}$ and $\mathrm{G}$.

Seed collected each year from the nutritional lines was sown in I959 in npk compound fertiliser with lime to establish whether any changes had occurred from year to year. The sixteen nutritional 
lines from the four years 1955, 1956, 1957 and 1958, were grown in six replicates, each divided into two blocks, fertiliser combinations with lime being placed in one block and combinations without lime in the other; each block contained eight sub-blocks consisting of the eight combinations of $\mathrm{N}, \mathrm{P}$ and $\mathrm{K}$, and each sub-block contained

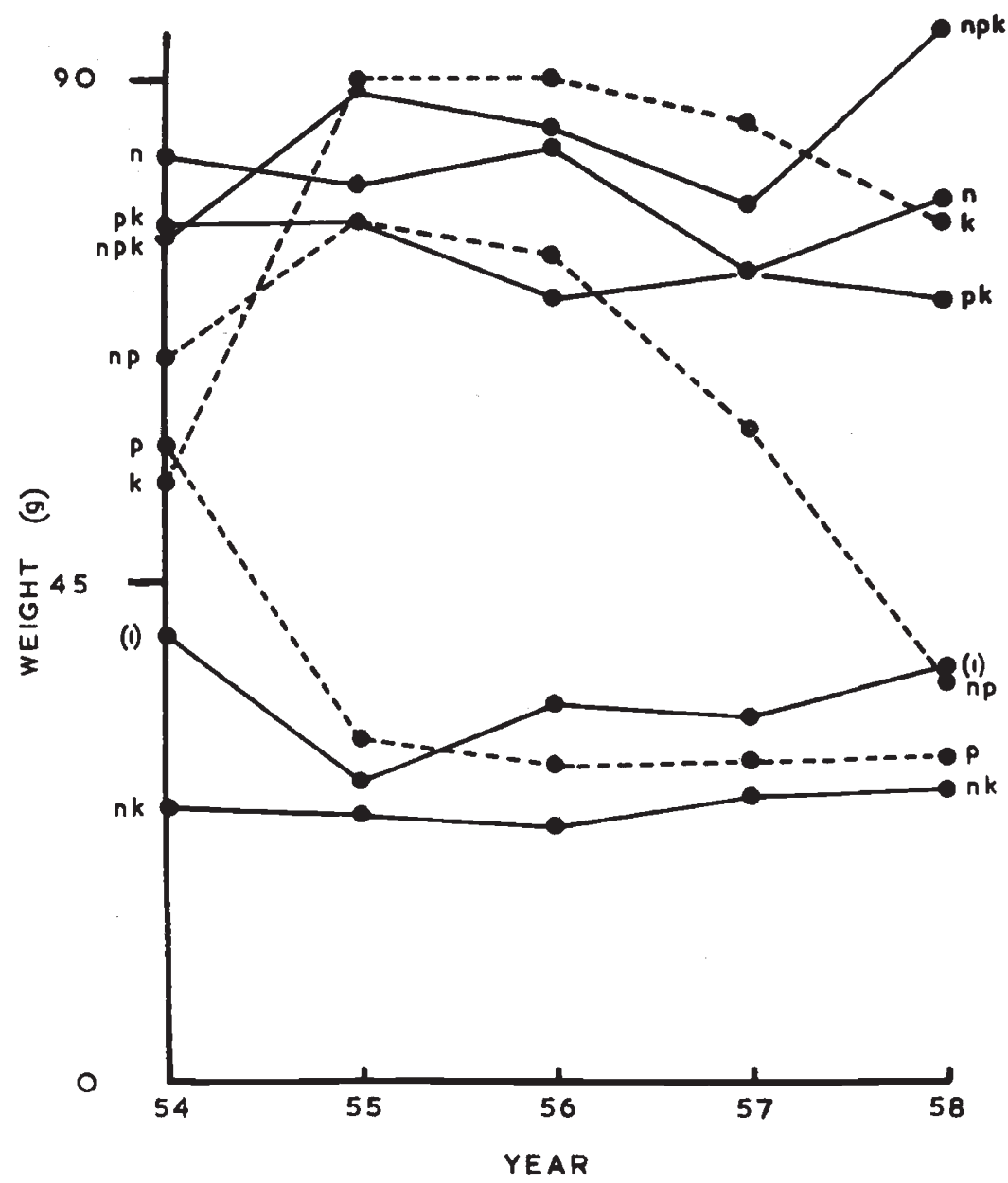

FrG. 6A.-Mean plant weights of progeny grown under similar conditions of five generations of nutritional lines. Each nutritional line was grown in one of the eight combinations of N, P and $\mathrm{K}$ without lime from 1954 to $195^{8}$.

four plots consisting of the four years. There were five plants in each plot, giving 1,920 plants altogether.

The weights of the plants are shown in figs. $6 \mathrm{~A}$ and $6 \mathrm{~B}$, where are also entered the weights of $\mathrm{C}_{154}$ (from which all the other plants are descended) given by the column totals in table 2, but scaled to remove the overall difference in plant weight between the 1955 and 1959 means.

Although there was no evidence in experiments described above 
for maternal effects being responsible for large differences in weight, the occurrence of a certain amount of maternal influence on the first generation is likcly to occur and might be expected to be more pronounced in an experiment of this type wherc plants are maintained in strongly contrasting environments for scveral generations, and

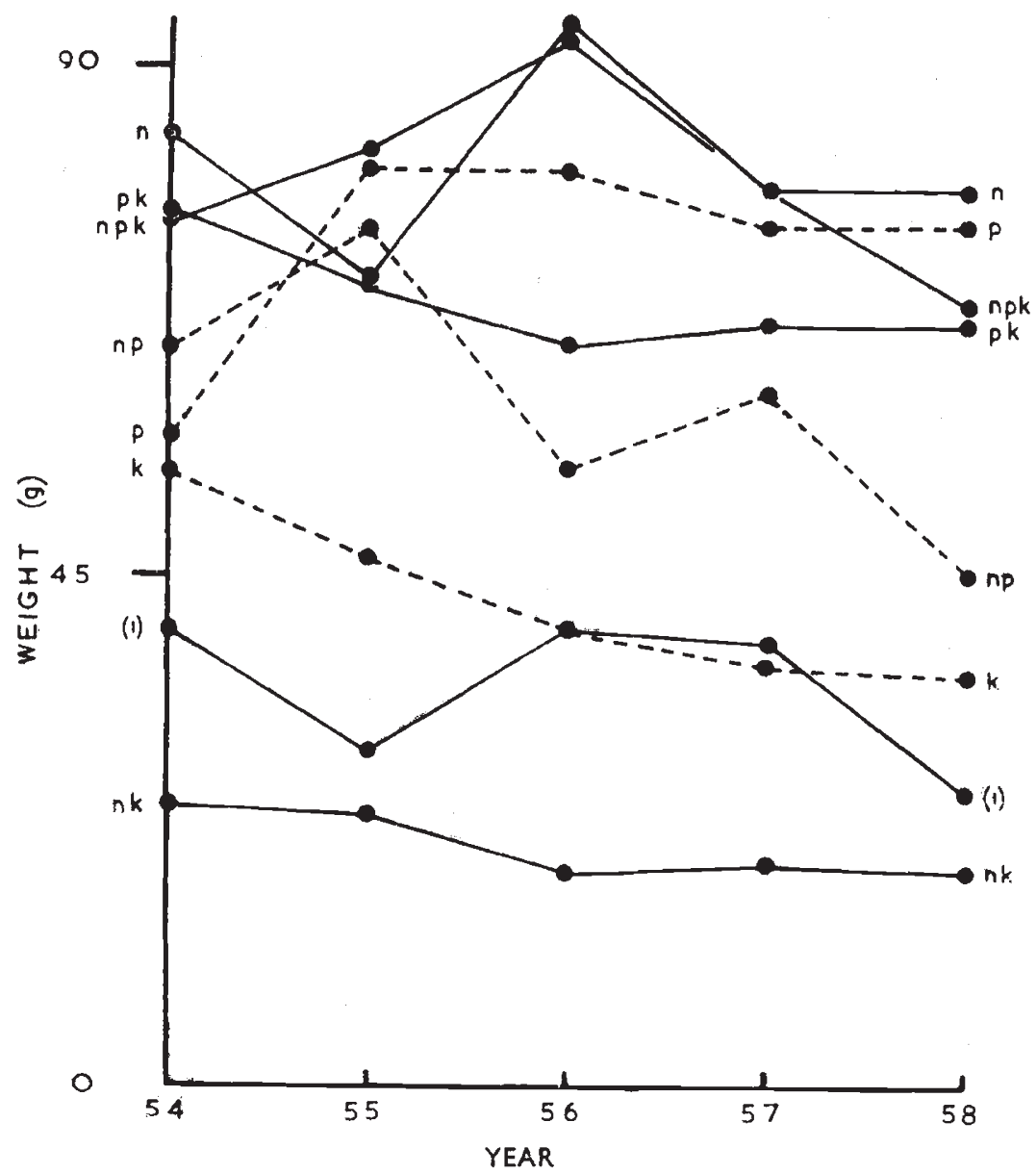

FIG. 6B.-Mean plant weights of progeny grown under similai conditions of five generations of nutritional lines. Each nutritional line was grown in one of the eight combinations of $\mathrm{N}, \mathrm{P}$ and $\mathrm{K}$ without lime in 1954 and with lime from 1955 to $195^{8}$.

figs. $6 \mathrm{~A}$ and $6 \mathrm{~B}$ arc to be viewed with caution. In both figures, $\mathrm{nk}$ maintains a consistently low value throughout; (I) varies more but neverthelcss remains low. At the other extreme, npk, pk and $n$ remain high although they are somewhat variable. With calcium, p shows a sudden increase which is maintained thereafter; $\mathrm{k}$ declines slowly. Without calcium, $\mathrm{p}$ drops and $\mathrm{k}$ rises, both changes being maintained. The extreme types have remained constant while those of intermediate weight, $\mathrm{p}$ and $\mathrm{k}$, have changed, which is in agreement with the results of the experiments described above. np shows a decline 
over the years, both with and without calcium. There was no previous evidence for the plasticity of np yet its occurrence here need not be regarded as an exception for $\mathrm{C}_{154 \mathrm{np}}$ has a plant weight near to those of $\mathrm{C}_{154} \mathrm{p}$ and $\mathrm{C}_{154} \mathrm{k}$. Calculation of the correlation coefficient of the regression coefficients, ignoring sign, of plant weight on year, with the deviations, ignoring sign, of the $\mathrm{C}_{154}$ types from the $\mathrm{C}_{154}$ mean, gives a value of $r=-0.78(P=2$ per cent.). That is, the greater the deviation from the $\mathrm{C}_{154}$ mean the smaller the consistent change in subsequent years, as concluded above.

Some counter observations can be made. With calcium, the fluctuations occurring in $\mathrm{n}$ are almost of the same magnitude as the initial rise in $\mathrm{p}$, while both with and without calcium, $\mathrm{np}$ rises first of all to values that might be thought characteristic of stable types. Maternal effects could be responsible for the fluctuations, due to the

TABLE 16

Mean plant weights ( $g$ ) of stable plants (npk and $n k$ ) and stock plants

\begin{tabular}{|c|c|c|c|c|c|c|}
\hline $\begin{array}{c}\text { Year } \\
\text { grown }\end{array}$ & $\begin{array}{c}\text { Fertilisers } \\
\text { applied }\end{array}$ & $\mathrm{npk}$ & $\mathrm{nk}$ & $\begin{array}{c}\text { Mean of } \\
\text { npk and nk }\end{array}$ & Stock & $\begin{array}{c}\text { No. of plants } \\
\text { of cach type }\end{array}$ \\
\hline 1958 & $\mathrm{npk}$ & 34 & 10 & 22 & 21 & 60 \\
1960 & $\mathrm{npk}$ & 38 & 14 & 26 & 27 & 40 \\
1960 & $\mathrm{p}$ & 78 & 10 & 44 & 42 & 40 \\
1960 & $\mathrm{nk}$ & $1 \cdot 7$ & 0.7 & $1 \cdot 2$ & $1 \cdot 2$ & 40 \\
\hline
\end{tabular}

large variation in seasonal conditions over the years affecting the quality (i.e. seed weight, germination vigour) of the seed, and the extremely dry conditions of 1959 when the experiment was carried out would emphasise these effects. The experiment itself is not sensitive in the sense that reliance is placed upon the basic fertility of the soil to change, and then only in specific directions, to provide environmental differences from year to year.

Taking all factors into consideration, the results on average do support the conclusion from previous experiments in attributing plasticity to the intermediate types and stability to the extremes. There is no evidence that the types become adapted to their individual environments and, apart from the change shown by $\mathrm{np}$, perhaps the other feature of interest is the difference calcium makes in the response to phosphorus and potassium.

\section{Experiment 10-Comparison of stable types with plants grown from the stock seed}

If the plastic types have intermediate weights, then plants grown directly from the original stock seed, which was used in the first place to demonstrate the changes, should also be intermediate in weight. In $195^{8}$ plants from stock seed were grown in npkg together with npk and nk plants which were descended from $\mathrm{G}_{154} \mathrm{npk}$ and 
$\mathrm{C}_{1} 54^{\text {nk }}$ respectively and which had been grown subsequently in npkg for two years. Three similar experiments were carried out in 1960 but grown in $\mathrm{npk}, \mathrm{nk}$ and $\mathrm{p}$ respectively. The plant weights given in table 16 are in perfect agreement with expectation throughout.

Summarising, these five experiments confirm the occurrence of differences in plant size of descendants of plants receiving fertiliser treatments and give almost overwhelming evidence for the occurrence, under the conditions in which the experiments were carried out, of plastic types which are intermediate in size between the stable types.

\section{DISCUSSION}

A number of experiments have been described demonstrating the heritability of changes produced by the application of fertiliser treatments to a single variety of flax. The transmission does not occur every time but the circumstances can be resolved into a pattern which allows prediction as to whether transmission will occur or not. The transmitted responses to the fertiliser treatments are in general in the same direction in all the experiments and such exceptions that do arise can be accommodated.

Reviewing the experimental results, in the first experiment all combinations of $\mathrm{N}, \mathrm{P}$ and $\mathrm{K}$ were used, and a spectrum of plant weights was obtained in the first generation. The extreme (stable) types bred true but those of internediate weight (plastic types) were capable, after treatment with fertilisers, of producing plants of both high and low weights in the following generation. In these further experiments on the plastic types, npk, nk, p and (I) fertiliser combinations were used, and the transmitted responses were in the same direction as in the first experiment except that $\mathrm{p}$ produced a small type of plant instead of an intermediate type. When these four combinations of treatments were again applied to plants grown from the original stock seed at about the same time as these later experiments, small plants were produced by $p$ here as well, so that the difference in response to phosphorus must have been due to different environmental conditions occurring at the two times, the most likely cause being the decline in soil fertility. A study of sixteen nutritional lines (plants grown in the same environments for several generations) showed that no adaptation occurred but gave further evidence for the existence of plastic and stable types. The original stock seed agreed with these observations in giving rise to plants which were plastic and intermediate in weight. In crossing and grafting studies the stable types behaved like orthodox genetic types giving no evidence of maternal or cytoplasmic inheritance.

Four alternative hypotheses were put forward earlier to explain the transmission. These were, (i) maternal inheritance, (ii) chance assortment of genetic factors, (iii) selection for genetic factors (on the assumption that in these last two cases there was a large amount of residual genetic variability in the variety) and, (iv) environmentally 
induced heritable change. In view of the repeatability of the results, chance assortment of genetic factors can be removed from further consideration.

If maternal inheritance is defined as the direct influence on the next generation by the transmission from the female parent of nutrients by reason of seed size, mineral content, etc., then this hypothesis can also be excluded for three reasons. The differences are maintained for several generations; reciprocal crosses between the extreme types have the mid-parent value; and the progeny of reciprocal grafts are unchanged. If we include with maternal inheritance the transmission by the female parent of different hormones, or different concentrations of hormones, built up in the parental environments, which have a direct effect on the next generation, these also should suffer dilution over several generations and in the reciprocal grafts, and the reciprocal crosses should be like the female parents. If it be supposed that hormones, having a direct effect on the next generation, are equally effective when transmitted through the pollen or through the egg cell, then the reciprocal crosses would have the mid parent value but dilution effects would again become apparent.

If certain nutrients or hormones built up by the parent plant have an indirect effect then dilution need not necessarily occur. If, for example, a nutrient or hormone is transmitted equally by the male and female parents and is capable of differentiating the plant at an early stage, as the seed ripens on the parent plant, or somewhat later, the differentiated plant would have the same characteristics as its parents and manufacture the same nutrients or hormones, the early differentiation overriding any influence of the environment in which the plant is grown. This could continue from generation to generation indefinitely. Although the reciprocal grafts were made at an early age it could be assumed that the stock and scion were already differentiated, but further assumptions would have to be made for the progeny of the stock and scion to retain their individual characteristics. The hormones or nutrients must remain almost completely localised, or diffuse very slowly from one to the other, or act only in those cells which are linearly descended from the early differentiated tissue which gave rise to the hormone. Differentiation has to be postulated and once postulated is sufficient in itself to provide an explanation, and an hormonal interpretation becomes superfluous. Hormonal differences may well occur between the types but they cannot satisfactorily be considered to be responsible for the transmission from one generation to the next, and are more likely, in this context, to be the result, rather than the cause, of differentiation.

Differentiation implies heritable change, which leads to the examination of the remaining two alternative interpretations; selection for genetic factors and induced heritable change. Assuming large residual genetic variability in the variety, infallible selection each time by the treatments for chromosomal factors, at some stage prior 
to seed formation, is unlikely, although it has not been disproved. Selection for heritable cytoplasmic particles could have occurredin view of the known influence of the environment on such particles in unicellular organisms where the environment may influence differcntially the rates of division of ccll and particles-or the particles themselves may have undergone change. Equilinear inheritance would require that they are transmitted equally through the pollen and the egg cell, or if fewer in number in the pollen, divide more rapidly at some subsequent stage. Equilincar inheritance suggests that the nucleus is implicated, and the nucleus must be taken into consideration in any case because of the biochemical inter-relationship between the nucleus and the cytoplasm, and of the influence the environment can have on the activity of the nucleus through the intermediary of the cytoplasm, as, for example, in the environmentally induced antigen changes in Paramecium (Beale, 1954).

Where the chromosomes are homozygous and discounting mutations, possible nuclear changes may be roughly divided into three, not mutually exclusive, groups: (i) Structural; for example, multiplication of chromosome threads, quantitative differences in nucleic acid, amount of coiling in certain regions. None of these differences has been detected with the light microscope. (ii) Chemical; either in the nucleoplasm or in the chromosomes. (iii) Functional; the differential stimulation of chromosomal regions in their participation in metabolic activities by changes in the cytoplasm or in other parts of the chromosomes. It would be more reasonable to suppose that nuclear changes directed by the environment would fall into one or more of these categories rather than to assume that the environment selects infallibly certain members of a heterozygous set of chromosomes, or one chromosome of an heterozygous pair.

The induced changes in flax resemble differentiation in multicellular organisms. The intermediate, plastic type ( $\equiv$ undifferentiated cell) may be changed to a large stable type or a small stable type ( $\equiv$ differentiated cells) depending upon the environment in which it is grown. There is good evidence that the nucleus is involved in differentiation from nuclear transfer experiments, both in unicellular organisms (Danielli, Lorch, Ord, Wilson, 1955), and in multicellular organisms (King and Briggs, 1955), which may have their counterpart in the induced changes in flax, but with the characteristic difference that these survive meiosis.

Leaving on one side the question as to whether quantitative, chemical or functional changes have occurred in self-reproducing particles in the cytoplasm or in the nucleus, the most useful working hypothesis at this stage with regard to the changes in flax is that both cytoplasm and nucleus contribute in establishing a metabolic equilibrium when the plants are grown under certain environmental conditions which is not disturbed thereafter when the plants are grown within the range of environments supplied in these expcriments. 
Since the environmentally induced types parallel in heredity differences due to orthodox genetic factors, and to separate them from epigenetic changes, they may be referred to as genotrophs resulting from genotrophic change.

Turning to the effects of the individual fertilisers in inducing heritable changes, these need to be interpreted against the background of the inherent fertility of the soil. In the first experiment (table 2), phosphorus gave the greatest overall difference in the following generation, which suggests that alterations in nucleic acid synthesis might be primarily responsible for the inherited differences. On the other hand, the soil was relatively deficient in phosphorus, judged by the responses to the direct applications of the fertilisers, and the application of phosphorus to the parent plants may have merely allowed them to make better use of the nitrogen and potassium which were applied, or other minerals in the soil which were not applied. Phosphorus applied by itself produced plants of only intermediate size in the next generation, whereas nitrogen by itself produced the largest type of plant even though when applied directly to the plant it produced a relatively small type (table 2 ). Consequently nitrogen and not phosphorus may be primarily responsible for inducing large plants in the next generation. On the other hand, nk induces a large plant and pk a small plant, but it is probable that, judged from the appearance of seedlings, nk had an inhibiting effect on their growth from which they were not able to recover in the absence of phosphorus, and plants receiving phosphorus and potassium were able to take up and utilise the nitrogen which was available in the soil.

Pursuing this hypothesis, in later years, when there was less nitrogen in the soil, phosphorus applied alone gave the smallest type of plant, comparable with the nk type, even though the parent plants receiving the phosphorus were larger than the plants receiving any of the other treatments, including npk (tables 8, I4, I5). In the experiment assessing the nutritional lines, the $n p$ nutritional line, both with and without calcium, gradually decreased in plant weight (figs. 6A and 6B). Presuming that the np type had retained its plasticity, this would be due to the gradual loss of nitrogen from the soil so that the initial combination of nitrogen and phosphorus plus soil nitrogen, inducing a relatively large type, becomes progressively a combination of nitrogen and phosphorus with only small amounts of soil nitrogen to induce a relatively small type. On this assumption, the character of the progeny is dependent upon the relative concentrations of nitrogen and phosphorus applied to the parents. Phosphorus without nitrogen produces large parent plants but induces small plants in the next generation; nitrogen without phosphorus produces small parent plants but induces large plants in the next generation. When nitrogen is limiting, and when plants are stimulated to grow rapidly with the application of phosphorus, perhaps the synthetic sequence, nitrogen-amino-acid-protein (enzyme), is also 
limiting. This parallels the situation in bacteria where enzyme induction only occurs when there is a sufficient supply of nitrogen in the media. In all ways this may be an over-simplified interpretation. Clarification is required of the interactions of nitrogen and phosphorus with calcium and potassium and of other soil nutrients, and of the negative parent/offspring correlation.

Considering the general application of these results, in some respects flax is unique among crop plants. The commercial varieties have not been selected for plant, root, stem or leaf weight, nor for fruit or seed yield, but for a long stem with few side branches and little seed production, containing cellulose fibres of commercial quality, and grown under conditions favouring these characters, that is, in soils of not high fertility and at seed rates producing on average one plant to the square inch. These are conditions which might be expected to produce plants of intermediate size compared, under suitable conditions, with plants obtained by selecting for large and small plant weights. In these experiments the plastic type was intermediate in weight compared with the stable types to which it gave rise. Selection for large plants, or maximum seed yields, may produce plants containing more stable heritable factors, so that although these may supply suitable homogeneous and homozygous material they may be less suitable for this type of investigation. Individuals in a natural population might be expected to vary in their ability to transmit changes to their offspring in response to environmental stimuli due to both genetic variability and to differences in the environmental history of their ancestors.

The above generalisation is probably only partially correct for the contrast drawn between flax and other crop plants does not necessarily mean that other crop plants are incapable of changing. In the first place, although exceptionally large doses were applied in these experiments, it is possible that at some time in the environmental history of the ancestors of the stock seed used, conditions of high or low fertility, or excess of nitrogen or phosphorus, were encountered which should, according to the above reasoning, have produced stable types. In the second place, flax seed is not necessarily obtained from a flax crop, but from specially cultivated plants. Mercer (1948) states, "First-class fibre and first-class ripe seed may not be produced from the same crop". A climate suitable for flax growing is not suitable for flax seed production and as a consequence flax seed has in the past been imported into Northern Ireland. It is not certain how relevant these observations are to the present discussion but it is certain that factors other than nutritional should be taken into consideration, and in particular, temperature.

The precaution was taken of growing the first generation of plants of the original stock seed in 1953 in boxes in ordinary soil taken from the field, and left in the open. Plants of subsequent generations, receiving the fertiliser treatments ivere grown for the first few weeks 
in a heated greenhouse where the temperature during the day and night was considerably higher than outside, and it is more than likely that the heritable responses are due to the combined effects of temperature and nutrition. Exploratory experiments suggest that this is true. Similarly, the stable types may not be stable when placed in the correct combination of temperature, nutrition and day length, but revert to the plastic type. This might give rise to a situation where a sequence of environments is required to produce the large from the small, so called, stable type. On the other hand, those plants which have been shown to be extreme types under the conditions of the experiments described here, do not necessarily differ in appearance in all environments, although breeding tests demonstrate that they are different. Further discussion on this topic would be to trespass beyond the results presented in this paper.

In discussing the authenticity of the inheritance of acquired characters in higher organisms writers have stated the paradox inherent in the concept:-if the environment is capable of changing plants in one generation then it should be equally capable of changing them again in the next generation, and therefore there should be no observed inheritance of acquired characters. It becomes more acceptable when modified to:-changes produced in parent organisms by some environments may reappear in the offspring when grown in some environments. One is dealing therefore with the degree of permanency of heritable factors, where the concept of heritable factors encompasses the frequency, composition, activity and interaction of nuclear and cytoplasmic particles.

It is of advantage to the organism for heritable factors to vary in their permanency for, at one extreme, it is able to retain its overall character, balance and evolutionary gains, and at the other, to adapt itself rapidly to current environmental conditions within its lifetime. Temporary differences occurring between offspring of parents grown in different environments are generally classified as maternal effects, but in some cases they may be due to neritable factors differing only from these in the flax experiments in being more transient. The same may apply to differences between reciprocal crosses, particularly when these are in opposite directions to the maternal parents, as occurs in some flax and linseed crosses in certain environments (Durrant, unpublished). Lints (1960) has also demonstrated this in Drosophila melanogaster. In Drosophila too there may be a balancing, or compensating, mechanism (Durrant, I955b, details to be published), which prevents the organism swinging too far in one direction. Even diurnal endogenous rhythms in Drosophila parents can be recorded in the offspring (Durrant, unpublished). This is a marginal region where genetic and maternal (nutritional) inheritance meet.

Heritable factors responsible for the differences between the flax types result from the interactions of the environment with other heritable factors, permanent and transient, contained in the plant. 
There are several aspects to the question as to whether they are permanent in the same way as chromosomal genes. The two extreme types of flax have remained stable for six generations under the conditions of these experiments irrespective of the nutritional environment. In appearance, uniformity, and reciprocal crosses and grafts, they behave as two distinct genetic types, although it is possible that they would revert if the right combinations of all the environmental factors were supplied. Presumed genetic differences between other plants could conceivably have arisen in the same way.

If the changes are nuclear, as mentioned above, they may be due to interaction of the nucleus with the cytoplasm or to alterations in the chemical composition of the chromosomes or, as discussed by Mather (196I), in nuclear substances associated with the chromosomes. For the environment to be directly concerned in evolution other than as a selective agent, changes in the more permanent chromosomal material would be necessary, either directly, or indirectly by way of the associated material which is then eventually incorporated into the more permanent chromosomal structure. On this view, fixation need not be immediate but related to the time of exposure to the specific treatments. Although there is no evidence at present, complete reversion of a genotrophic change may not always be possible. Instead, small amounts of additive and accumulative variation might be fixed in each generation which would contribute to the overall genetic variability determining quantitative variation. By analogy, homeostatic changes in metabolism associated with gene mutations at other parts of the chromosomes might also be permanently fixed, so that there would arise several heritable changes at the one time. In any case, the environment would have an indirect evolutionary effect, for, apart from inducing the genotrophs, selection by the environment would act differentially on them, and for mutations occurring within them. On outcrossing the genotrophs, new genetic constitutions could permanently fix the environmentally induced changes, as also could the environmental selection for specific genes if the changes had been induced in heterozygous populations.

It is difficult to say how far these results are compatible with those described by eastern geneticists until unequivocal information is available on the details of their experimentation, and on how much segregation of chromosomal factors contributed to the differences. The occurrence of plants that may be plastic or stable depending upon the particular set of environments being investigated, and upon their ancestral environmental history, could lead to confusion in the interpretation of the lack of repeatability of results.

As regards crop improvement, although larger and smaller plants have been obtained from the original flax variety, neither of these may be better economically than the original, intermediate type.

The environments supplied, and experimental procedures adopted were those most convenient for preliminary experiments. Other 
experiments which are in progress fall into four main groups: ( 1 ) Critical assessment of the environmental factors-minerals, temperature, light intensity, day length-concerned in the induction, and possible reversion, of heritable change. (2) Assessment of crosses between stable types and between stable and plastic types grown in different environments to obtain information on the interactions between environment, cytoplasm and nucleus. (3) Induction of heritable changes in other species and individuals from natural populations. (4) Biochemical and physiological studies on the stable and plastic types, and studies on the effect of growth hormones, their behaviour in different environments and on crossing with other varieties.

\section{SUMMARY}

Under the conditions detailed, heritable changes have been induced in a flax variety by growing the parent plants in different combinations of fertiliser treatments. A plastic type is defined which is changed into a larger form or a smaller form, depending on the fertiliser applied. Both the large and the small forms are stable and have remained unchanged for several generations under the condition of these experiments, irrespective of the fertilisers subsequently supplied.

The three types are termed genotrophs. The plastic genotroph, and probably the stable genotrophs, have these properties only within a particular range of environments. When the small and large genotrophs are reciprocally grafted and reciprocally crossed they behave like two distinct genetic types, and the nucleus is probably involved in the genotrophic change.

Analogies are drawn with enzyme induction in micro-organisms and differentiation in multicellular organisms. The balance of nitrogen and phosphorus in the nutrients applied plays at least some part, if not a major part, in the induction of heritable change.

The induction of heritable change is dependent upon the environmental conditions supplied and the plastic properties of the plant, the plastic properties being dependent upon its genetic constitution and the environmental history of its ancestors.

Flax has not been selected for grain yield nor plant weight and it is therefore likely to be more plastic than other crop plants where selection and environment may have resulted in the establishment of more stable types, but certain combinations of environmental factors involving nutrition, temperatures, day length and light intensity may be effective in inducing changes in these also. Inbred lines from natural populations would be favourable material for similar investigations provided no deliberate selection was employed and each was split into sub-lines kept in different environments during their establishment. 
Plate I

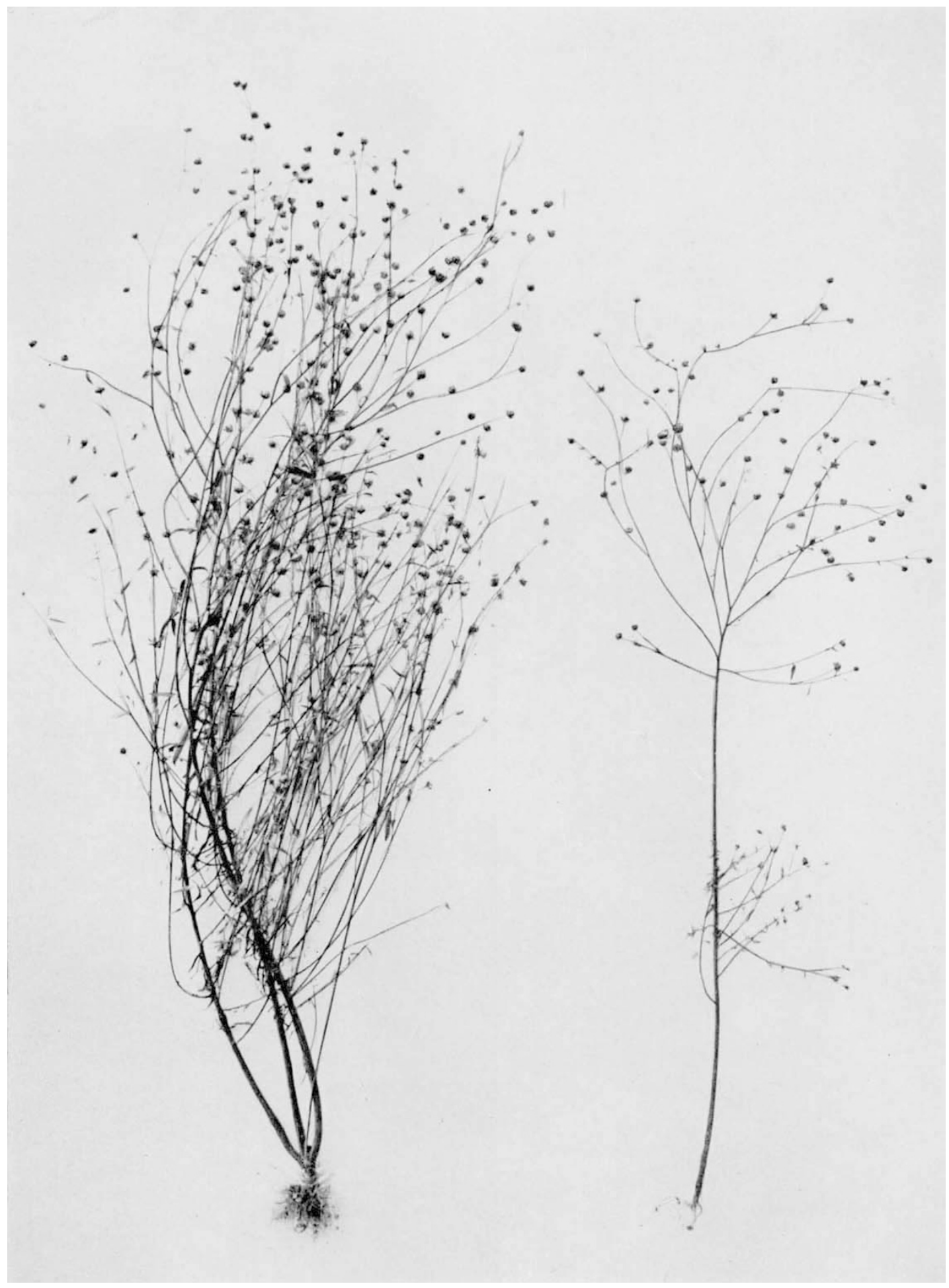

Fourth generation plants of two cxtreme types of flax induced by fertiliser treatments. Left, npk; right, nk. 


\section{REFERENCES}

AVERY, O. T., MACLEOD, C. M., AND MCCARTY, M. I944. Induction of transformation by a desoxyribonucleic acid fraction isolated from Pneumococcus Type III. Journal of Experimental Medicine, 79 (2), 137-158.

beAle, G. H. 1954. The Genetics of Paramecium aurelia. Cambridge University Press.

BRINK, R. A. 1956 . A genetic change associated with the $R$ locus in maize which is directed and potentially reversible. Genetics, $4 I, 872-889$.

BRINK, R. A., BLACKWOOD, M. B., AND NOTANI, N. K. I960. Effects of structural changes in the long arm of chromosome 10 in maize on paramutation of the $\mathbf{R}^{r}$ factor. Science, 131,1317 .

DANielli, J. F., LORCh, I. J., ORD, M. J., AND wilson, E. G. I955. Nucleus and cytoplasm in cellular inheritance. Nature, $776,1114^{-1115}$.

DURRANT, A. 1955a. Effect of time of embryo formation on quantitative characters in Drosophila. Nature, 175, 560 .

DURRANT, A. 195.5 b. Extra-nuclear inheritance in Drosophila melanogaster. (Abst.) Heredity, 9, 41 7.

DURRANT, A. 1958. Environmental conditioning of flax. Nature, 18x, 928-929.

hartman, P. E. 1957. Transduction : a comparative review. Symp. on the Chemical Basis of Heredity, 408-462. John Hopkins Press, London.

JiNks, J. L. 1954. The analysis of continuous variation in a diallel cross of Nicotiana rustica varieties. Genetics, 39, 767-788.

KING, T. J., AND BRIGGs, R. 1955. Changes in the nuclei of differentiating gastrula cells, as demonstrated by nuclear transplantation. Proc. Nat. Acad. Sci. U.S., 4 , $321-325$.

LINTS, F. A. 1960. Nucleo-cytoplasmic interactions in Drosophila melanogaster. Genetica, 3I, 188-239.

MAlogolow'Kin, CH., POULSON, D. F., AND WRIGHT, E. T. I959. Experimental transfer of maternally inherited abnormal sex ratio in Drosophila willistoni. Cienetics, 44, 59-74.

MATHER, K. 1961. Nuclear materials and nuclear change in differentiation. Nature, 190, 404-406.

MERCER, S. P. 1948. Farm and Garden Seeds. Crosby Lockwood and Son, London. PERCival, J. 1935. Agricultural Botany. Duckworth, London.

SCH.AIK, N. W. V., AND BRINK, R. A. 1959. Transposition of modulater, a component of the variegated pericarp in maize. Genetics, 44, 725-738.

SONNEBORN, T. M. 1950. The cytoplasm in heredity. Heredity, 4, II -36.

SPIEGELMAN, s., AND CAMPBELl, A. M. 1956. The significance of induced enzyme formation. Currents in Biochemical Research, 115-161. Interscience Publishers, London.

Waddington, C. H. 1956. Principles of Embryology. George Allen \& Unwin, London. 